\title{
HDlive Study of Fetal Development and Behavior
}

\author{
${ }^{1}$ Toshiyuki Hata, ${ }^{2}$ Kenji Kanenishi, ${ }^{3}$ Uiko Hanaoka, ${ }^{4}$ Rina Uematsu, ${ }^{5}$ Genzo Marumo, ${ }^{6}$ Hirokazu Tanaka
}

\begin{abstract}
We present the latest HDlive studies of fetal development and behavior during pregnancy. Marked changes of embryonic and fetal development and movement with advancing gestation were noted in the first trimester of pregnancy. Various realistic facial expressions (or facial movements) were recognized in the second and third trimesters. In particular, blinking, mouthing, swallowing, yawning, tongue expulsion, and sucking were clearly depicted. Moreover, various extraordinarily realistic features of fetal emotion-like behavior were identified. HDlive observation of fetal behavior and facial expressions may reflect the normal and abnormal neurological development of the fetus. HDlive may become an important modality in future research on fetal neurobehavioral development and assist in evaluation of the fetal brain function.
\end{abstract}

Keywords: HDlive, Fetal anatomy, Embryonic development, Fetal development, Fetal behavior, Fetal facial expression, Fetal emotion.

How to cite this article: Hata $T$, Kanenishi $K$, Hanaoka $U$, Uematsu R, Marumo G, Tanaka H. HDlive Study of Fetal Development and Behavior. Donald School J Ultrasound Obstet Gynecol 2014;8(3):250-265.

Source of support: Nil

Conflict of interest:

\section{INTRODUCTION}

There have been numerous studies on conventional threedimensional (3D) and four-dimensional (4D) ultrasound evaluation of the normally developing embryo and fetus and assessment of fetal neurobehavior at different gestational ages. ${ }^{1-3}$ With the latest developments in 3D/4D ultrasound technology, HDlive images of the embryo and fetus seem to be more readily discernible than those obtained by conventional 3D/4D ultrasound, because HDlive provides

\footnotetext{
${ }^{1}$ Professor and Chairman, ${ }^{2,6}$ Associate Professor

${ }^{3}$ Lecturer ${ }^{4}$ Sonographer, ${ }^{5}$ President

${ }^{1-4,6}$ Department of Perinatology and Gynecology, Kagawa University School of Medicine, Kagawa, Japan

${ }^{5}$ Department of Obstetrics and Gynecology, Marumo Ladies Clinic, Tokyo, Japan

Corresponding Author: Toshiyuki Hata, Professor and Chairman, Department of Perinatology and Gynecology Kagawa University School of Medicine, Kagawa, Japan, Phone: +81-0878912174, Fax: +81-0878912175, e-mail: toshi28@med. kagawa-u.ac.jp
}

physicians and sonographers with a natural and anatomically realistic appearance. ${ }^{4-9}$ HDlive is a new surface rendering mode which uses an adjustable light source that facilitates the ability to create lighting and shadowing effects thereby increasing depth perception. ${ }^{4}$ This technique provides such extraordinarily realistic imaging of the embryo and fetus that it is almost impossible to differentiate between actual photographs and sonographic images. ${ }^{10}$ Moreover, the observation of facial expressions using HDlive is considered to reflect the normal and abnormal neurologic development of the fetus. ${ }^{11}$ Therefore, HDlive may assist in evaluation of the fetal brain function, and offer a potential advantage related to conventional 3D/4D ultrasound.

The present paper describes the latest state-of-the-art on HDlive imaging of embryonic and fetal development and fetal neurobehavioral development, and makes recommendations for future research in this field.

\section{FETAL DEVELOPMENT}

In normal pregnancy, morphological and anatomical development of the embryo and fetus can be clearly depicted in the first, second, and third trimesters of pregnancy (Figs 1 to 23). The spatial relationships between the embryo and yolk sac can be clearly identified between 6 and 10 weeks (see Figs 1 to 8). The fetal facial anatomy can be identified at 12 to 13 weeks of gestation (see Figs 10 and 11). Various realistic fetal facial and other anatomical structures can be noted in the second and third trimesters (see Figs 12 to 23).

\section{Weeks}

HDlive shows the embryo to be a solid, comma-shaped structure adjacent to the yolk sac in the gestational sac at 6 weeks' gestation (see Fig. 1). ${ }^{6}$ The yolk sac is bigger than the embryo at this age.

\section{Weeks}

A prominent forehead is evident, and the upper and lower limbs are clearly depicted (see Figs 2 and 3). The upper limb buds develop 2 days before the lower limb buds. ${ }^{12}$ The embryonic head size is almost the same as the yolk sac. The umbilical cord and midgut herniation are also evident (see Fig. 3). The ability to view the embryo seems to be better with transvaginal HDlive compared with intrauterine 3D sonography. ${ }^{13}$ 

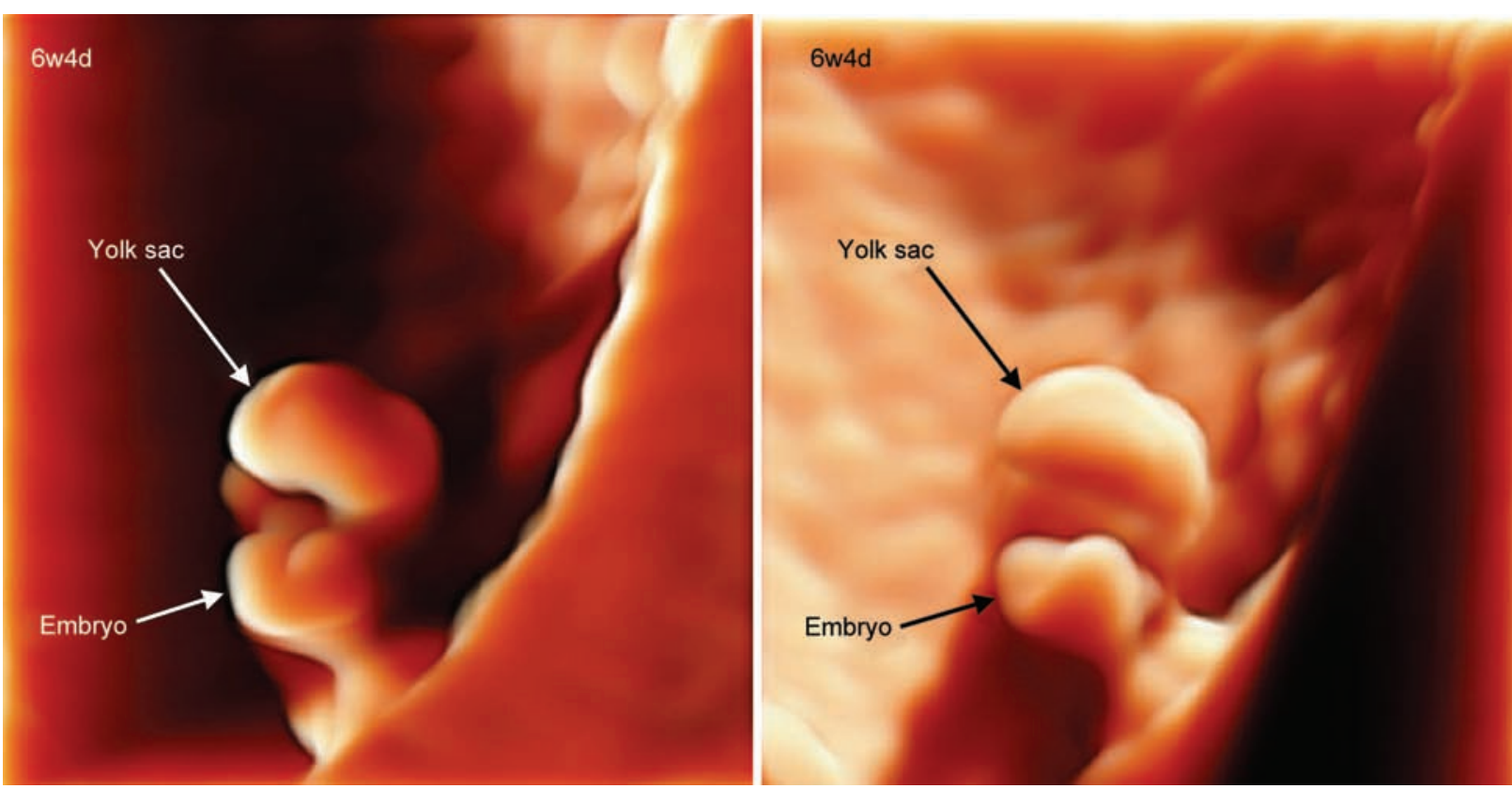

Fig. 1: HDlive images of the embryo and yolk sac at 6 weeks and 4 days of gestation. The crown-rump length is $3.3 \mathrm{~mm}$ (Courtesy: Reprinted with permission from Hata T et al) ${ }^{6}$
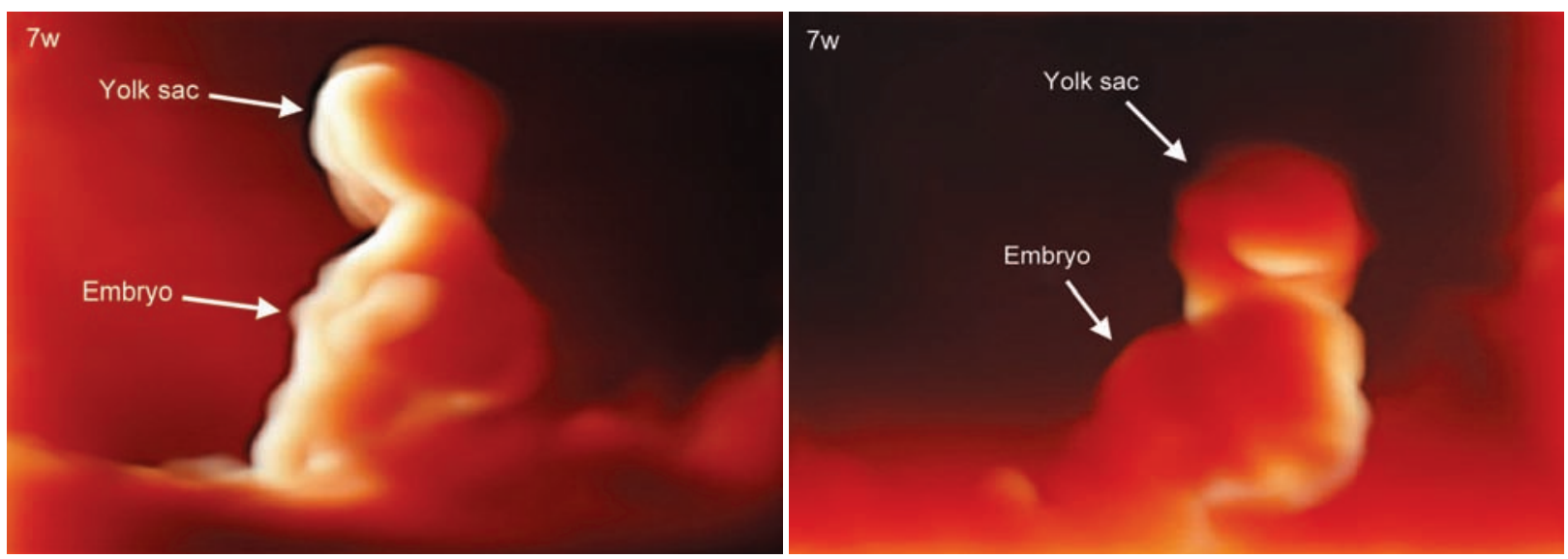

Fig. 2: HDlive images of the embryo and yolk sac at 7 weeks of gestation. The crown-rump length is $8.9 \mathrm{~mm}$

\section{8 to 11 Weeks}

HDlive allows anatomically realistic visualization of all structures of the conceptus, such as the embryo or fetus, umbilical cord, midgut herniation, amniotic sac, and yolk sac (see Figs 4 to 9). At 8 weeks, the distal ends of the limbs flatten into hand- and foot-plates, and the sacral tail protrudes caudally (see Fig. 5). At 10 weeks, earscan be noted (see Fig. 8).

\section{2 to 13 Weeks}

The fetal facial anatomical structures such as the eyes, nose, ears, and mouth are clearly evident at 12 to 13 weeks of gestation (see Figs 10 and 11). Nostrils and fingers can also be identified at 13 weeks of gestation (see Fig. 11).

\section{4 to 19 Weeks}

At 16 weeks of gestation, muscles involved in fetal facial expressions fully form. ${ }^{14}$ All anatomical whole-body

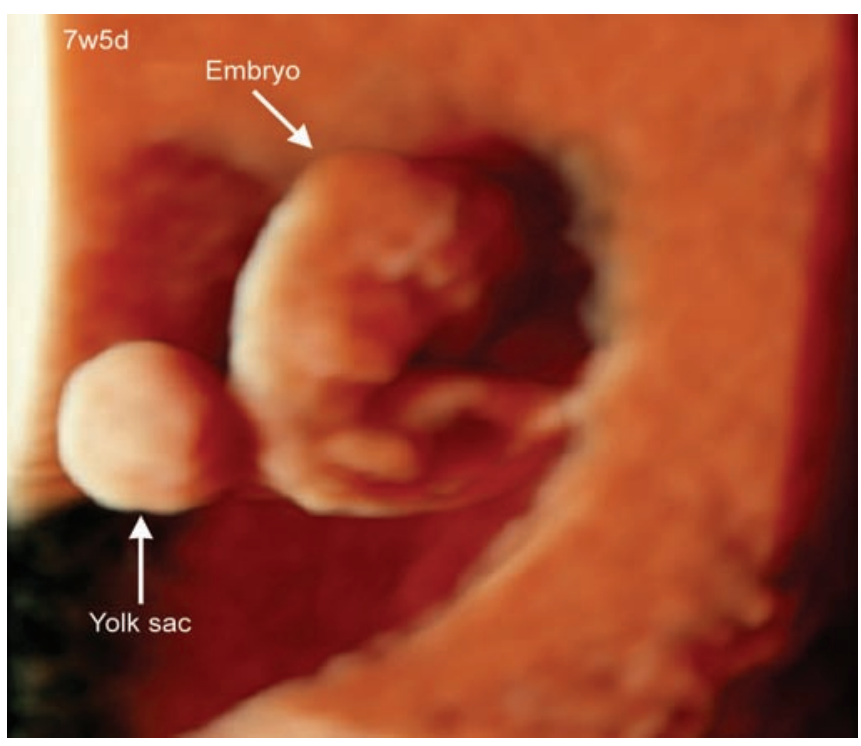

Fig. 3: HDlive image of the embryo and yolk sac at 7 weeks and 5 days of gestation (Courtesy: Reprinted with permission from Hata T et al) ${ }^{5}$ 


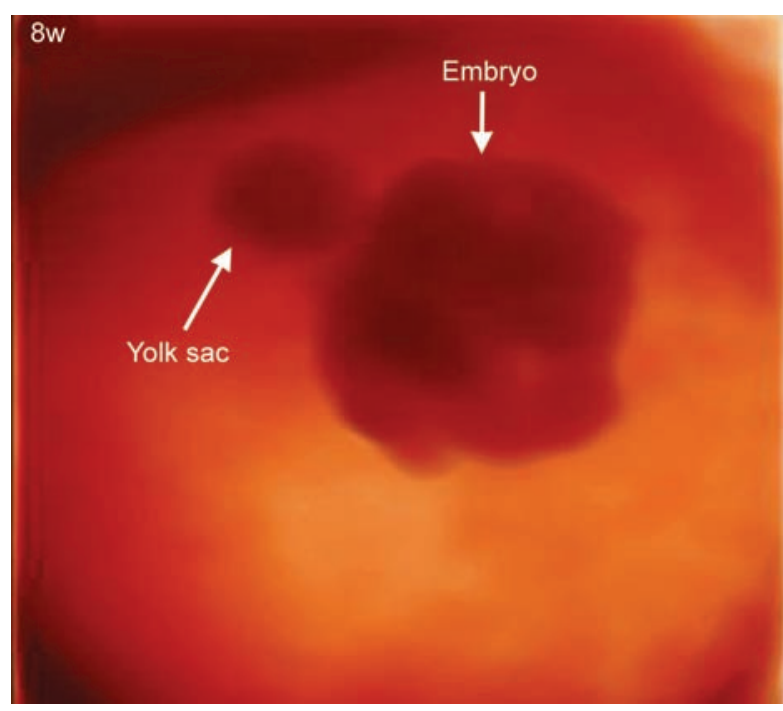

Fig. 4: HDlive image of the embryo and yolk sac at

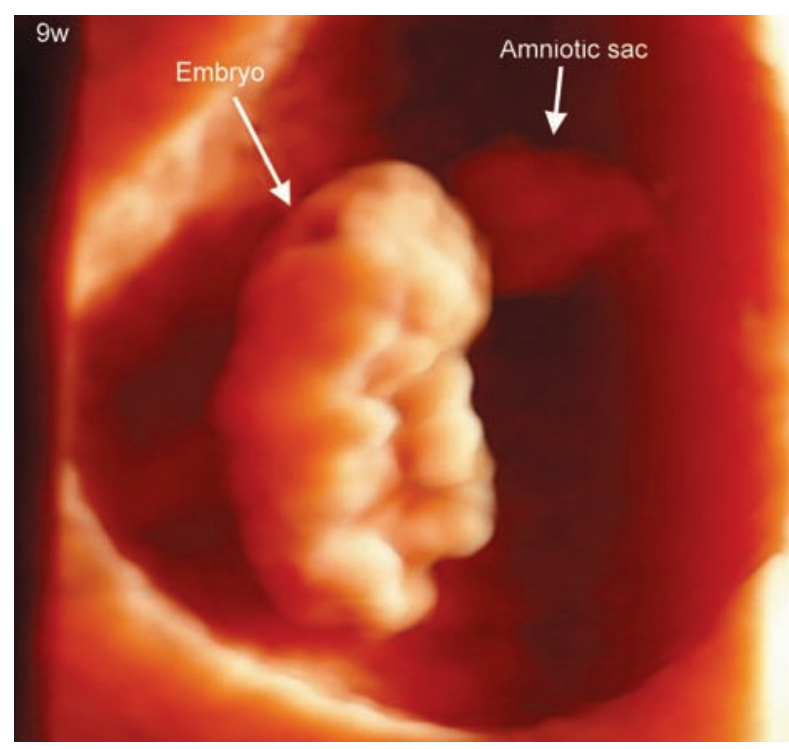

Fig. 6: HDlive image of the embryo at 9 weeks of gestation. fetus is in the amniotic sac (Courtesy: Reprinted with permission from Hata T et al) ${ }^{5}$ 8 weeks of gestation The embryo is in the amniotic sac
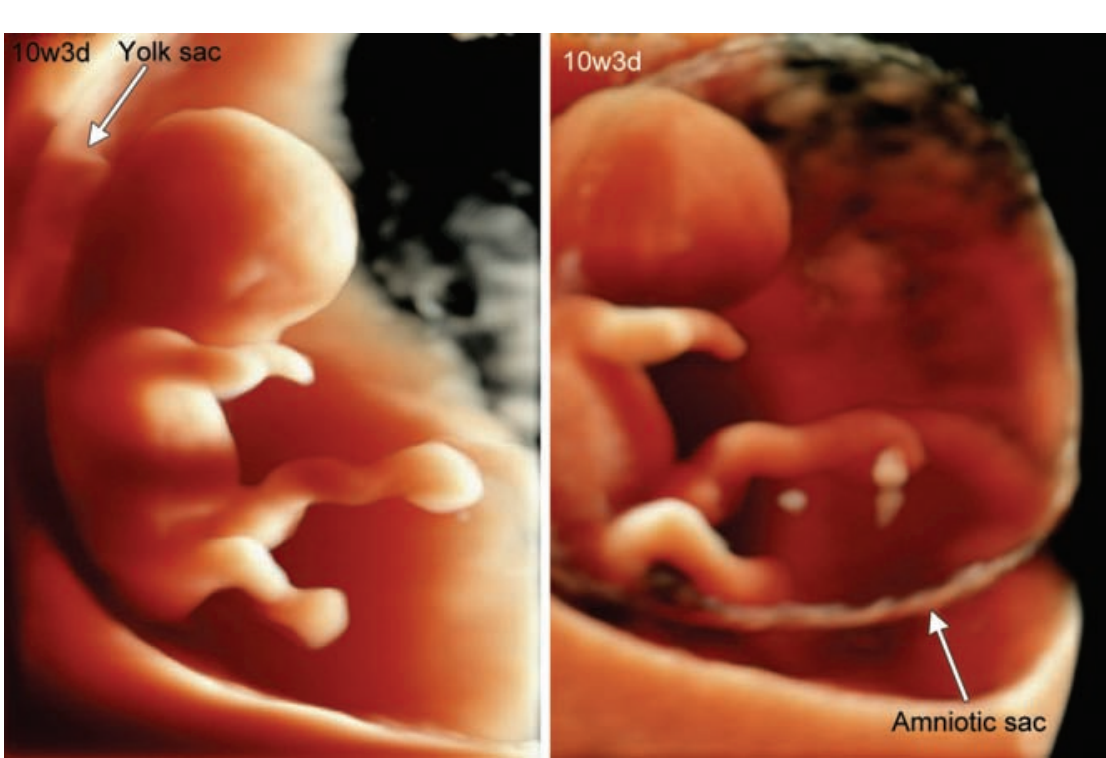

Fig. 8: HDlive images of the fetus and yolk sac at 10 weeks and 3 days of gestation. It can be clearly noted that the

Fig. 5: HDlive image of the embryo and yolk sac at 8 weeks and 6 days of gestation (Courtesy: Reprinted with permission from Hata T et al) ${ }^{5}$

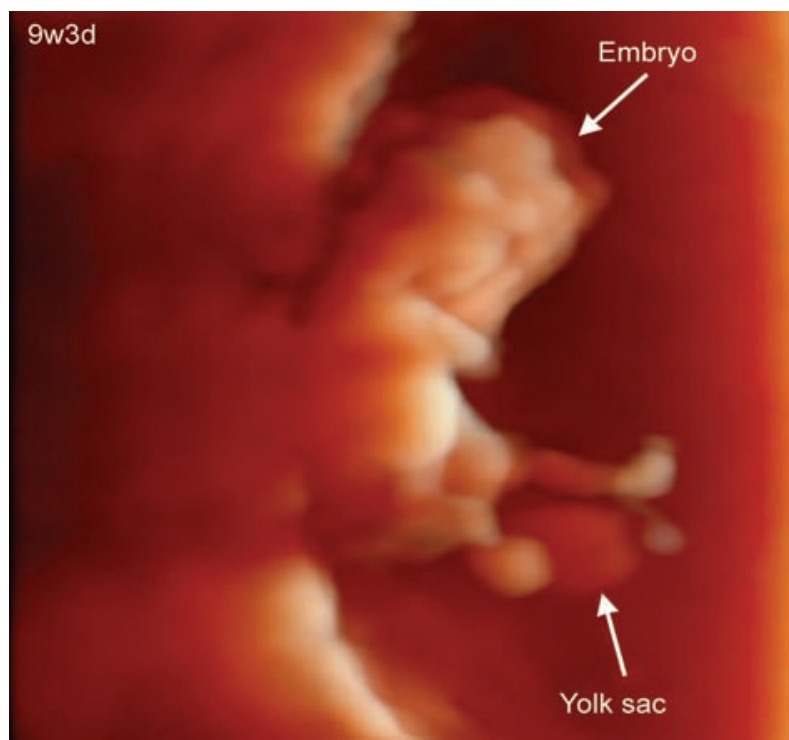

Fig. 7: HDlive image of the embryo and yolk sac at 9 weeks and 3 days of gestation (Courtesy: Reprinted with permission from Hata T et al) ${ }^{5}$ 


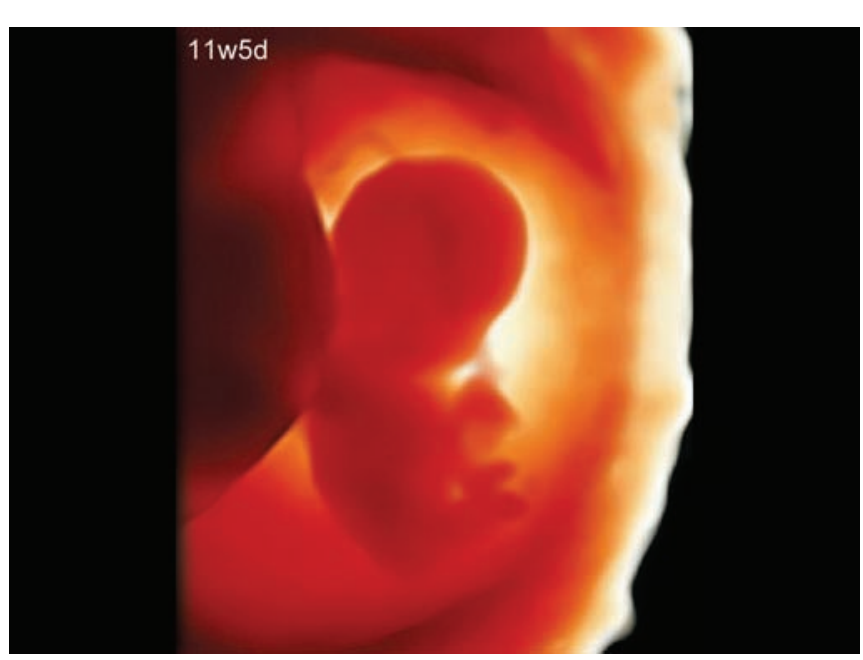

Fig. 9: HDlive image of the fetus at 11 weeks and 5 days of gestation

structures can be recognized early in the second trimester (see Figs 12 and 13). The placenta and umbilical cord are also evident.

\section{Weeks to Term}

Fetal facial adipose tissue is deposited and shows gradual accumulation between 24 and 36 gestational weeks. ${ }^{14}$ Realistic fetal faces can be noted after 20 weeks to term (see Figs 14 to 20). External genitalia are clearly identifiable in both males and females (see Fig. 21). In the male fetus, the penis, scrotum, and anus can be noted. In the female fetus, the labia minora, labia majora, and anus are evident. Hands and feet are also clearly evident (see Figs 22 and 23).

\section{FETAL MOVEMENTS IN THE FIRST TRIMESTER}

HDlive images of the embryo and fetus seem to be more readily discernible than those obtained by conventional 4D ultrasound in the first trimester of pregnancy, because HDlive provides a natural and anatomically realistic appearance of the embryo and fetus. ${ }^{5,11}$ HDlive observation of the embryo and fetus in the first trimester of pregnancy provides new
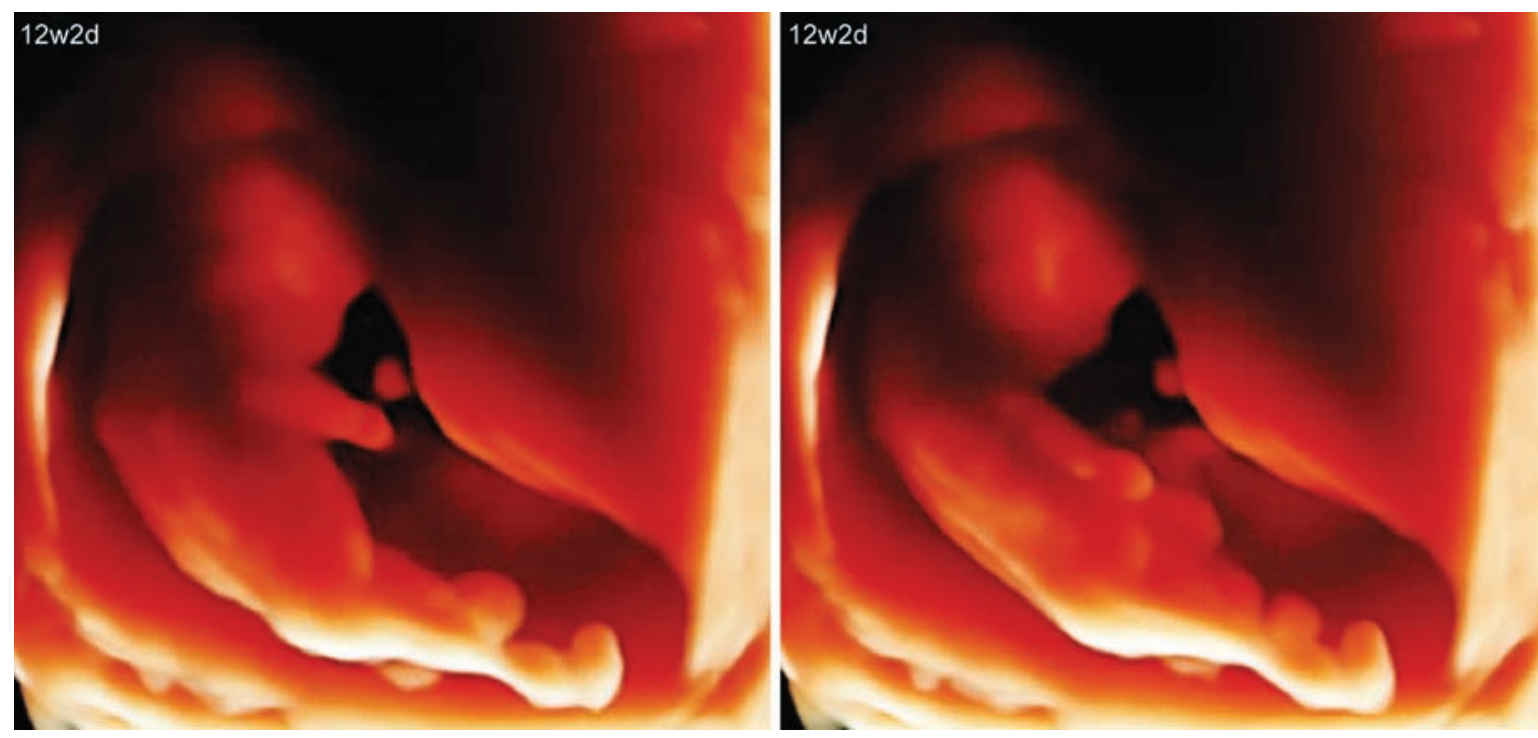

Fig. 10: HDlive images of the fetus at 12 weeks and 2 days of gestation
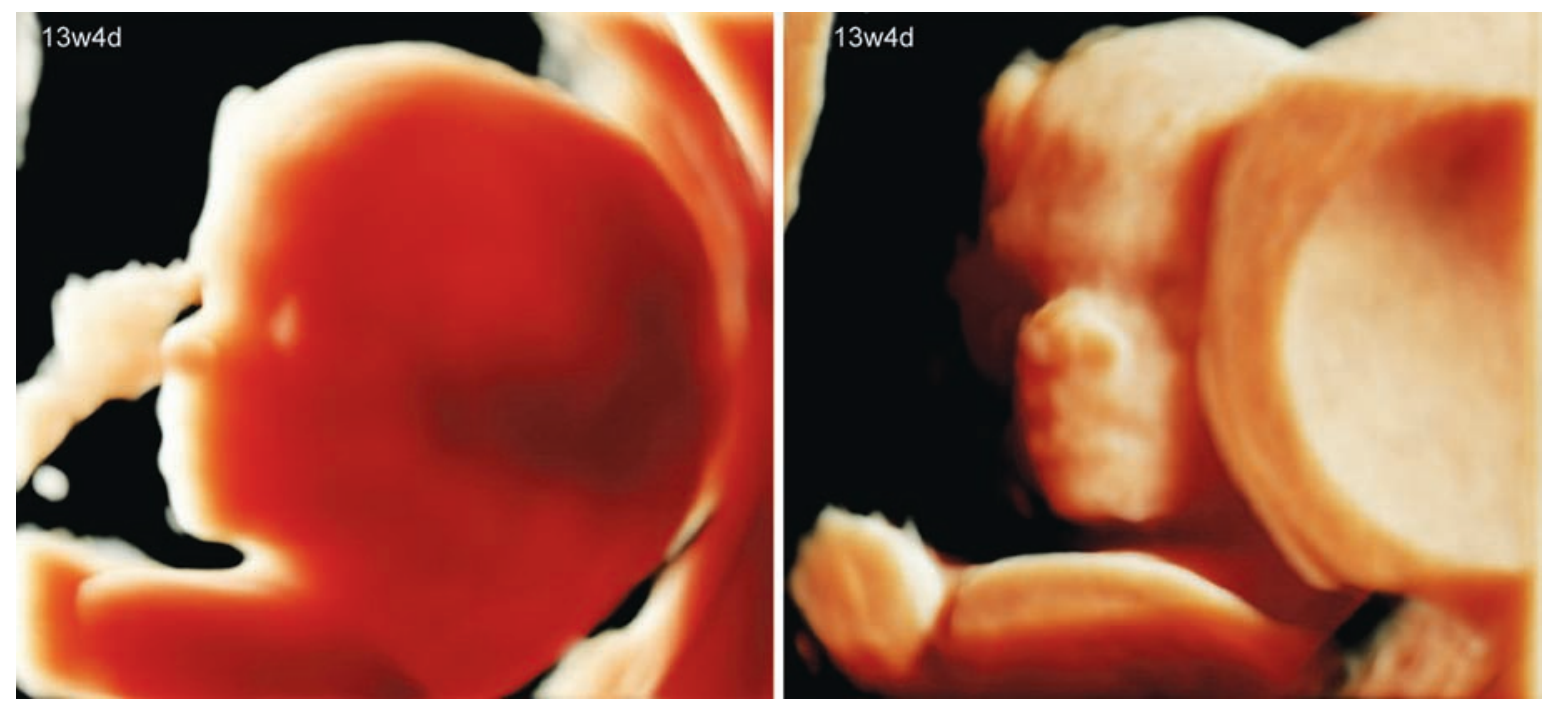

Fig. 11: HDlive images of normal fetuses at 13 weeks and 4 days of gestation. The fetal facial anatomy can be clearly identified (Courtesy: Reprinted with permission from Hata T et al) ${ }^{5}$ 

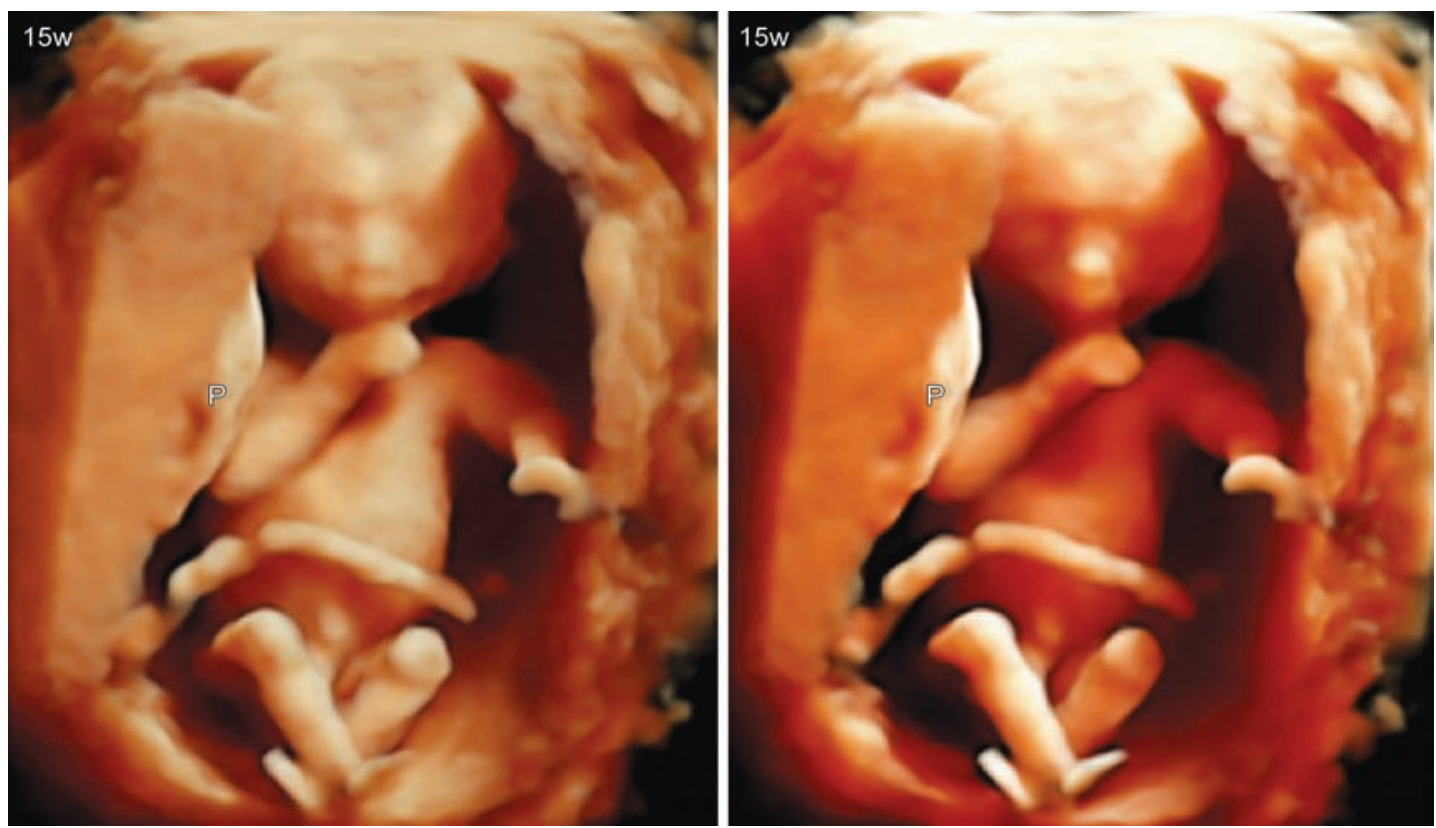

Fig. 12: HDlive images of the fetus at 15 weeks of gestation

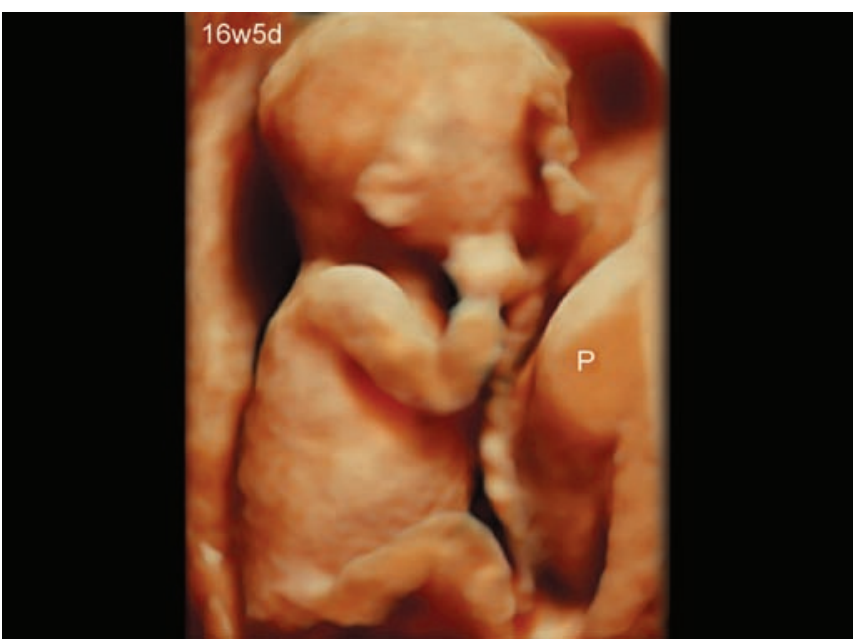

Fig. 13: HDlive image of the fetus at 16 weeks and 5 days of gestation

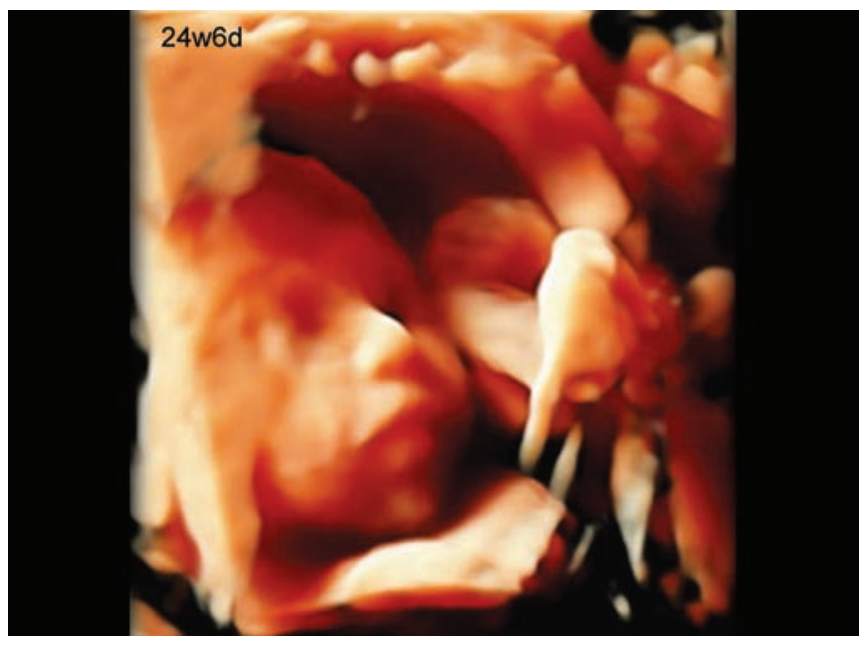

Fig. 15: HDlive image of the fetal face at 24 weeks and 6 days of gestation

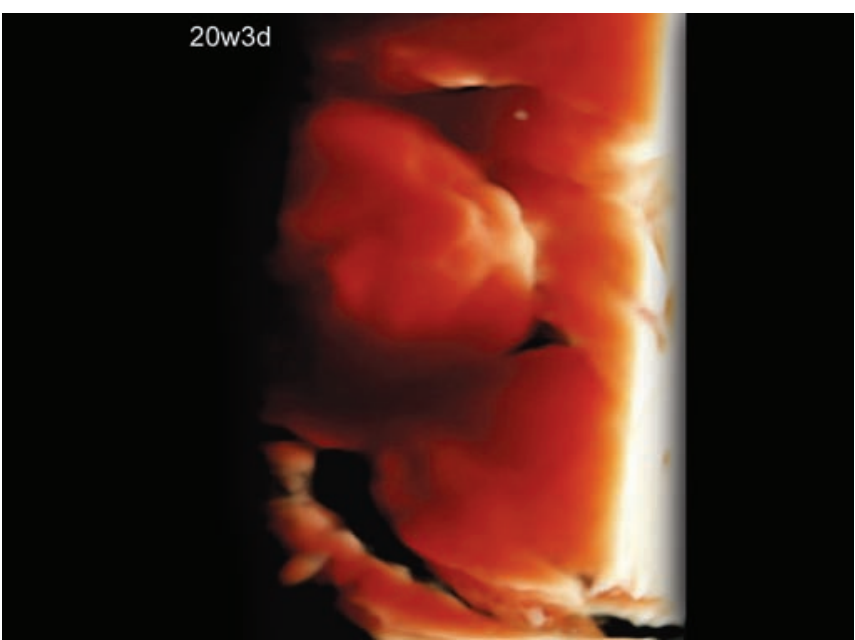

Fig. 14: HDlive image of the fetal face at 20 weeks and 3 days of gestation

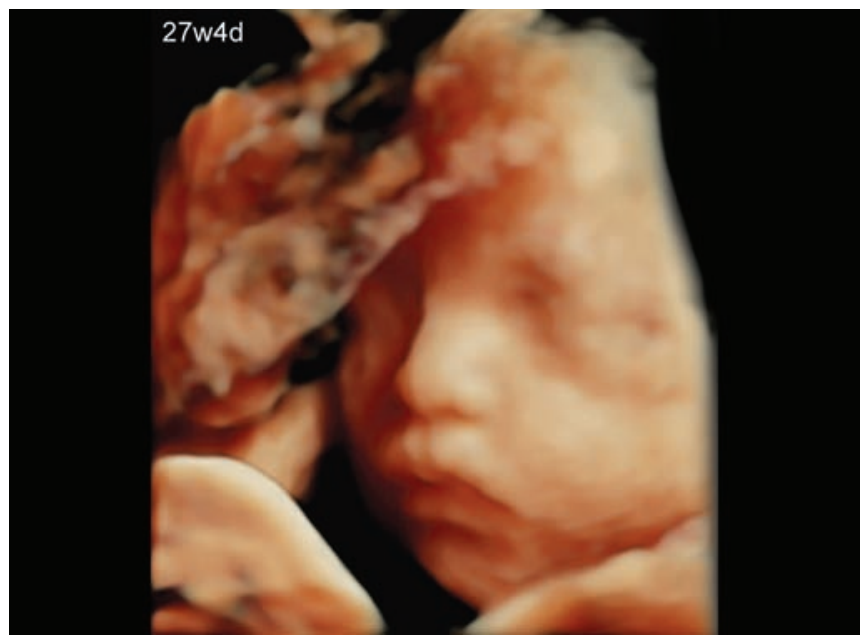

Fig. 16: HDlive image of the fetal face at 27 weeks and 4 days of gestation 


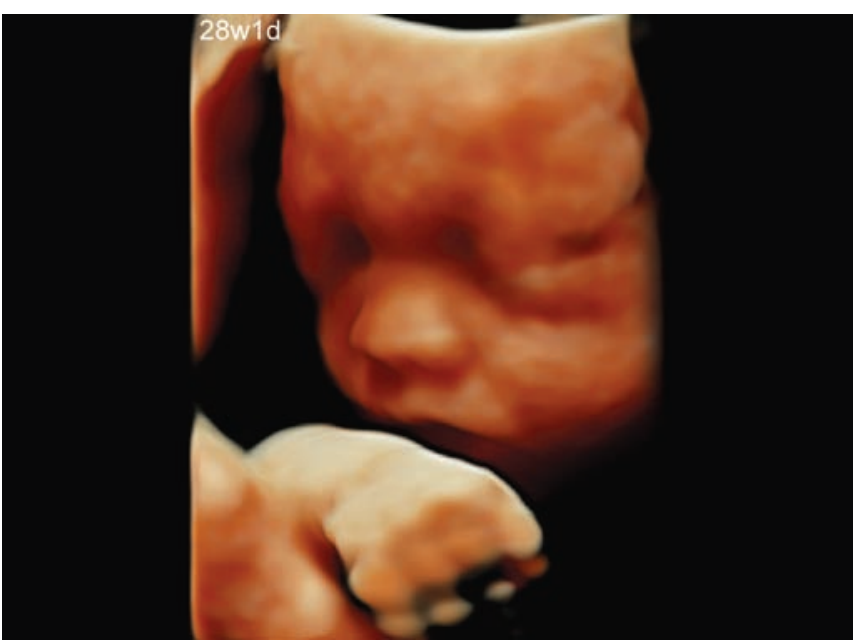

Fig. 17: HDlive image of the fetal face at 28 weeks and 1 day of gestation

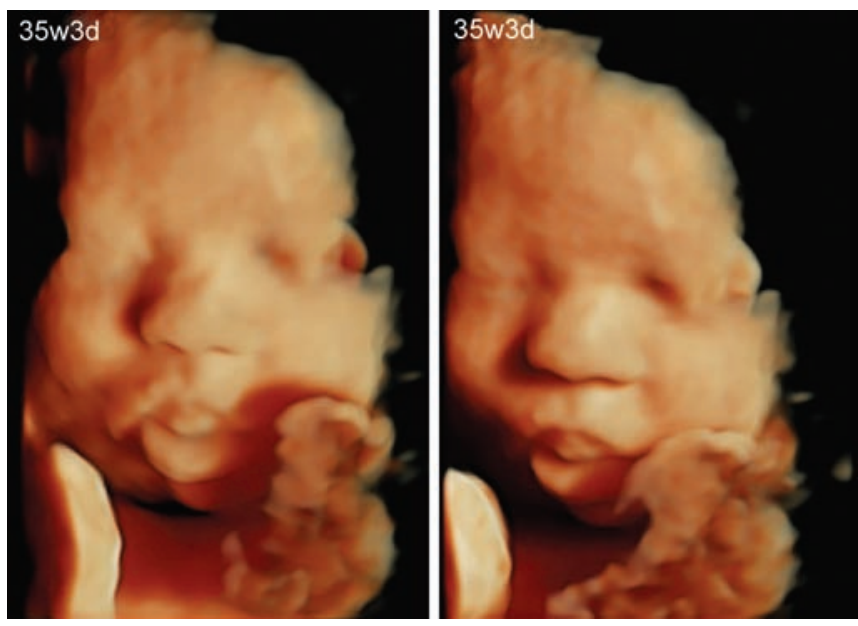

Fig. 19: HDlive images of the fetal face at 35 weeks and 3 days of gestation

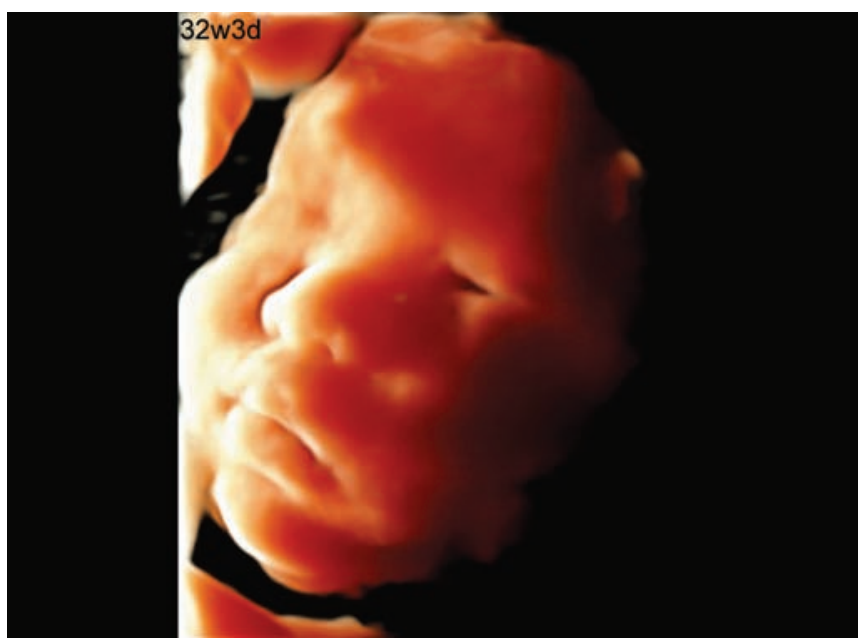

Fig. 18: HDlive image of the fetal face at 32 weeks and 3 days of gestation
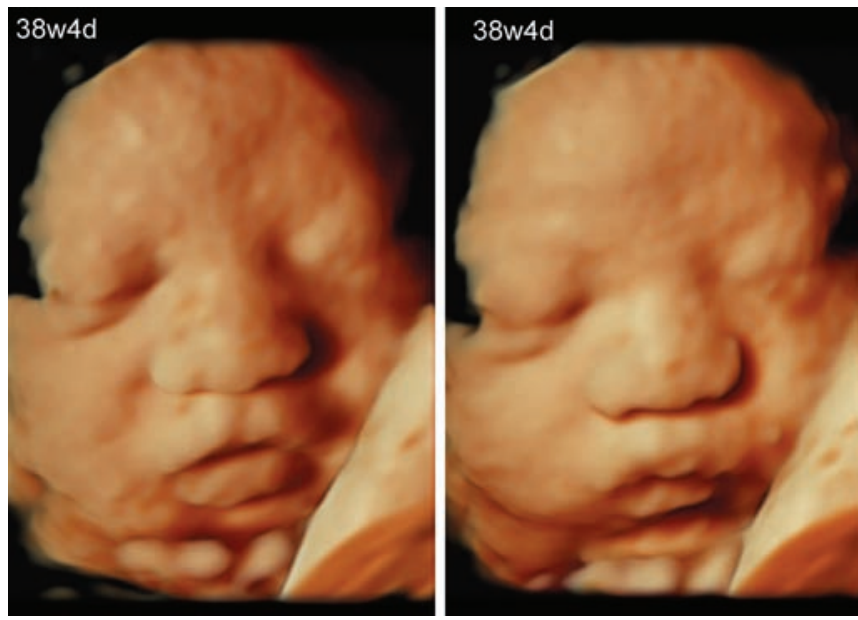

Fig. 20: HDlive images of the fetal face at 38 weeks and 4 days of gestation

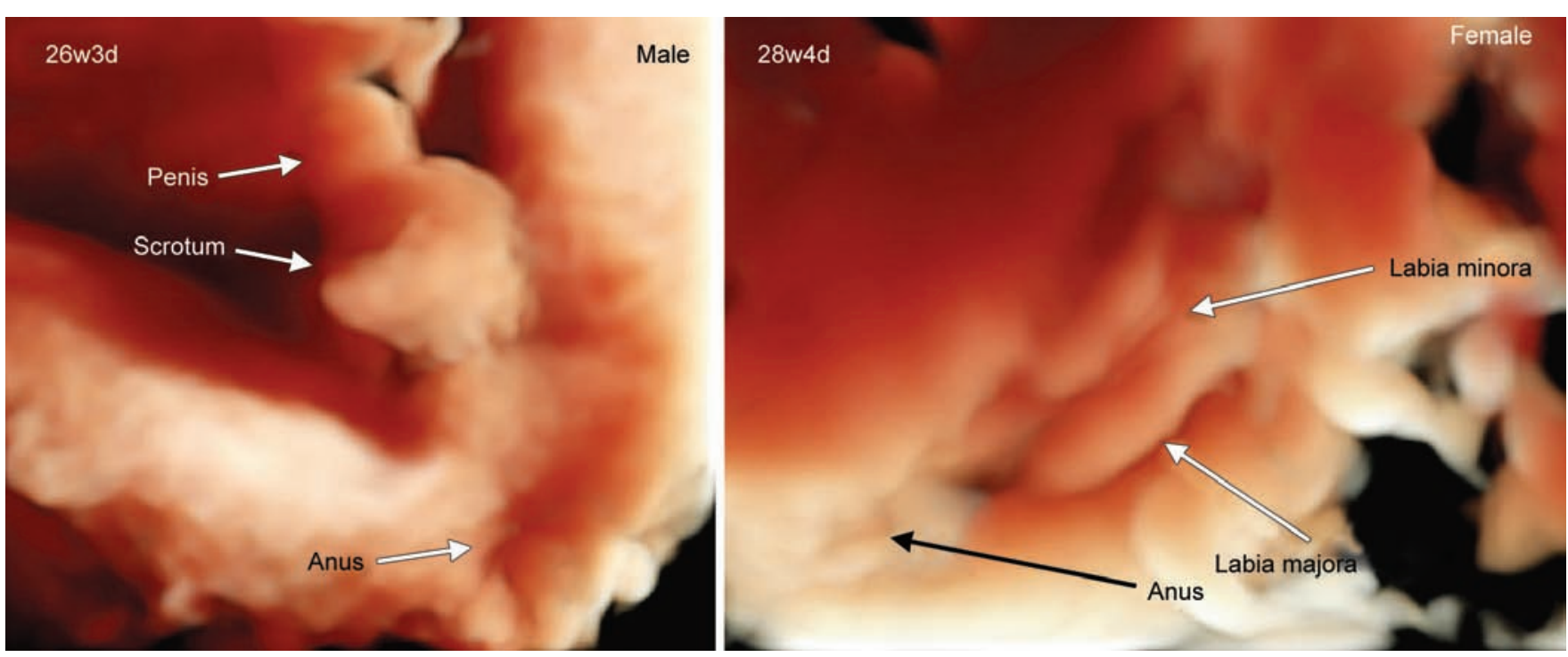

Fig. 21: External genitalia of both a male and female. In the male fetus, the penis, scrotum, and anus can be noted at 26 weeks and 3 days. In the female fetus, the labia minora, labia majora, and anus are evident at 28 weeks and 4 days 


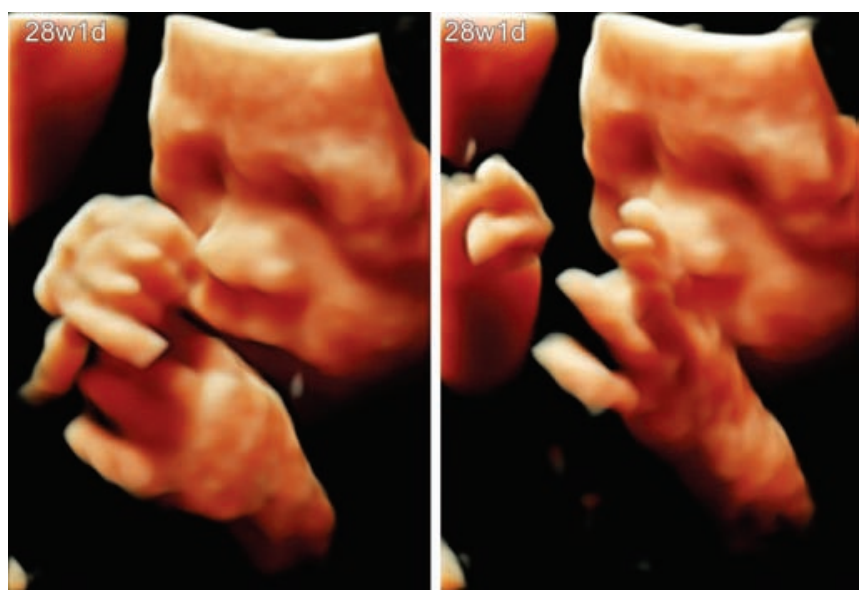

Fig. 22: Fetal hands at 28 weeks and 1 day
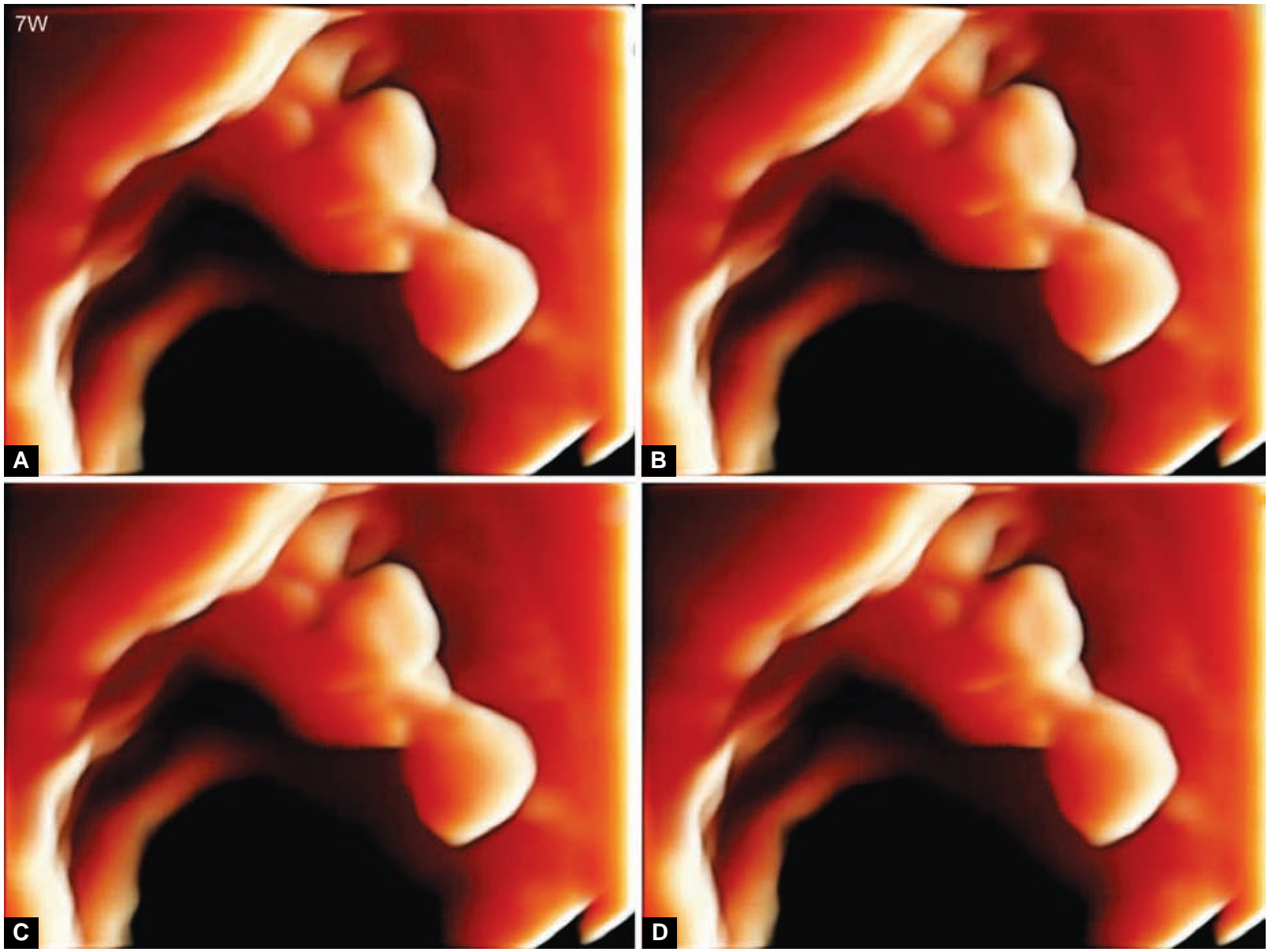

Fig. 23: Fetal right foot at 28 weeks

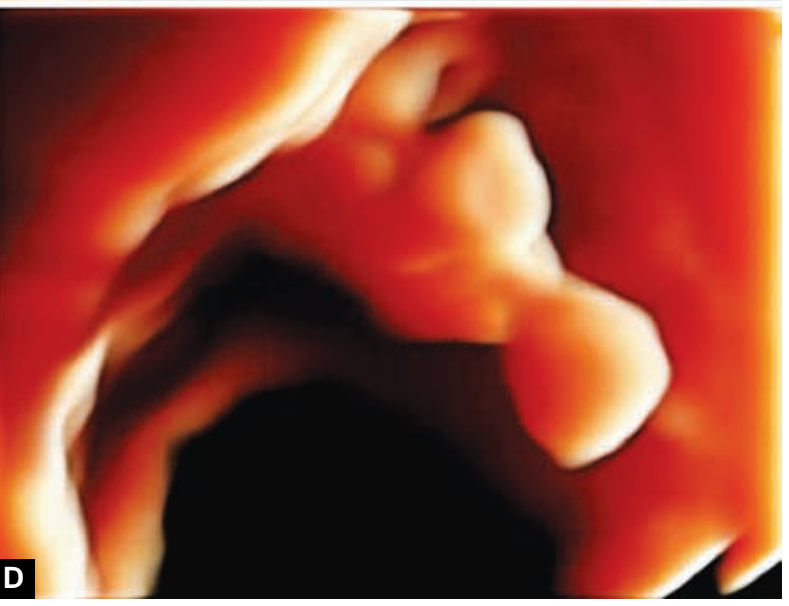

Figs 24A to D: Consecutive HDlive observations of a 7 weeks embryo. Only subtle limb movement can be noted and/or additional information to facilitate improved understanding and assessment of fetal movements. Moreover, new fetal movement may be detected using this technique.

\section{Weeks}

Only subtle limb movement can be noted (Figs 24A to D). However, sometimes, it is very difficult to notice embryonic movement at this age.

\section{Weeks}

Embryonic limb movements are clearly recognizable (Figs 25 and 26).

\section{Weeks}

The simultaneous occurrence of hand, foot, and trunk movements is evident (Figs 27A to F). 

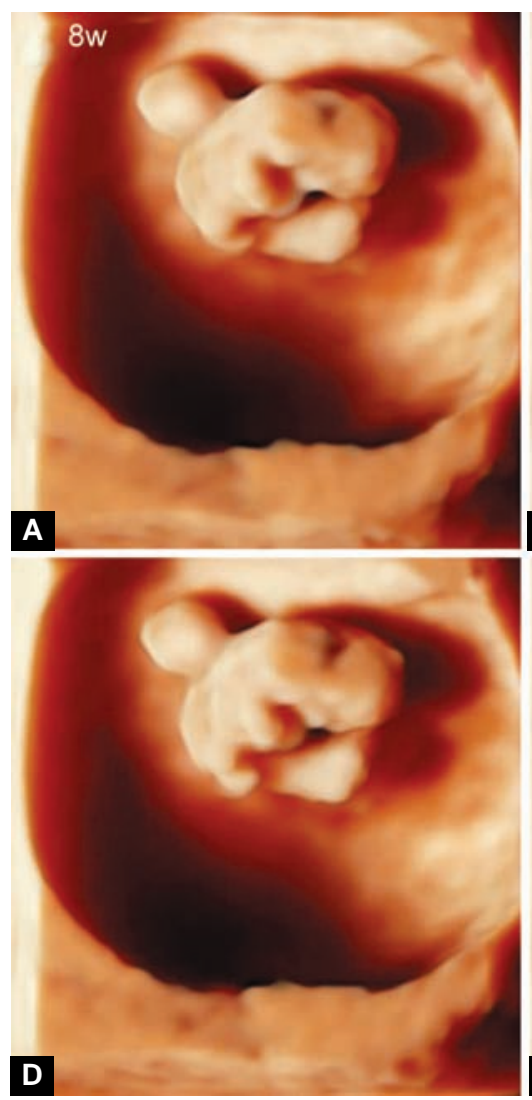

Figs 25A to F: Consecutive HDlive observations of an 8 weeks embryo. Embryonic limb movements can be clearly recognized at 8 weeks
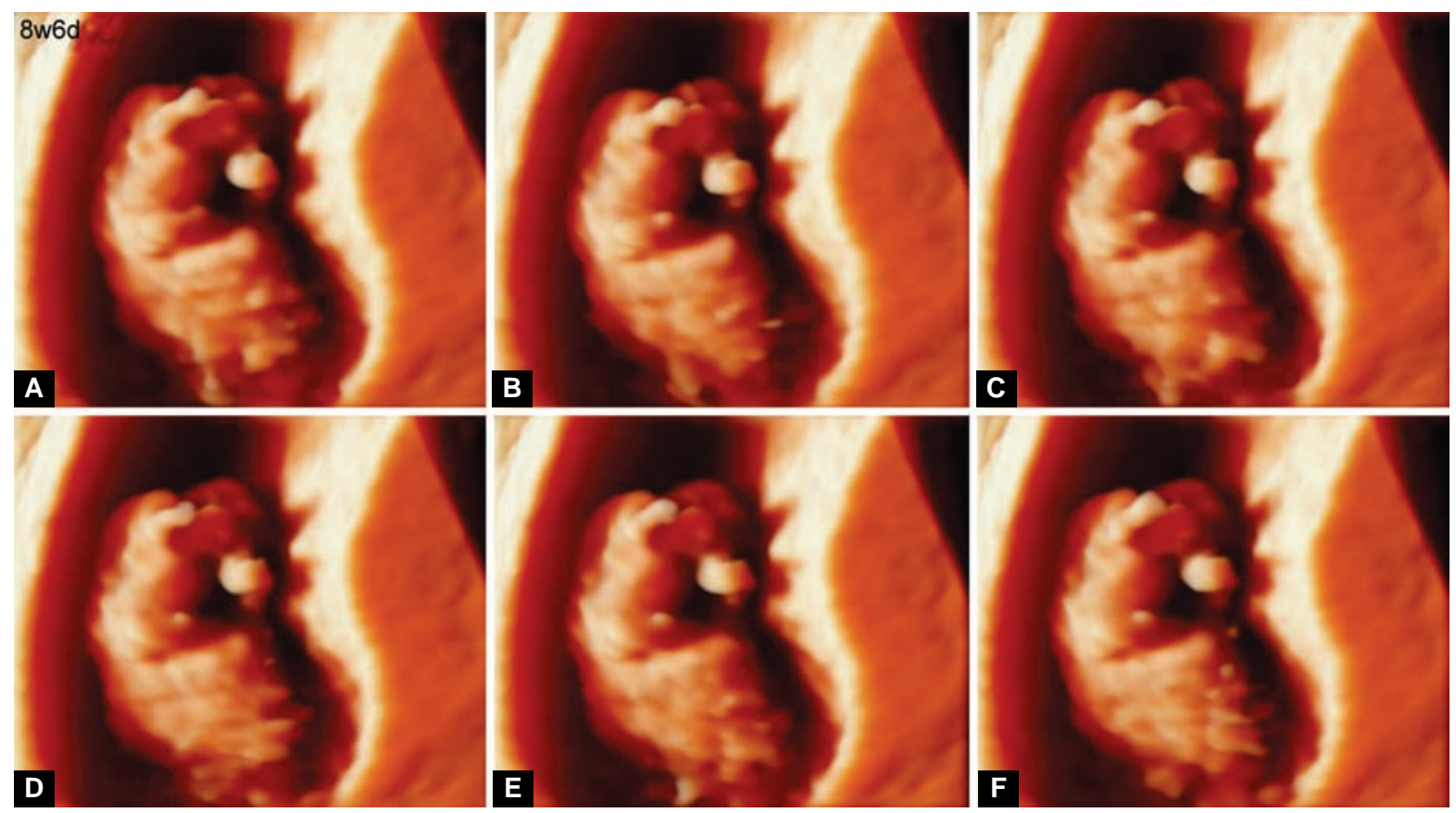

Figs 26A to F: Consecutive HDlive observations of an 8 weeks embryo. Embryonic limb movements can be clearly recognized at 8 weeks and 6 days

\section{0 to 13 Weeks}

Smooth and fluid head and trunk movements involving complicated hand and leg movements are clearly identifiable late in the first trimester of pregnancy (Figs 28 to 30). Sometimes, trunk bending is involved (Figs 30A to D).

\section{FETAL FACIAL EXPRESSIONS (FETAL FACIAL MOVEMENTS)}

HDlive provides extraordinarily realistic features of the fetal face. ${ }^{11}$ Fetal blinking (Figs 31 and 32), mouthing (Figs 33A to F), swallowing (Figs 34A to F), yawning (Figs 35 and 36), 

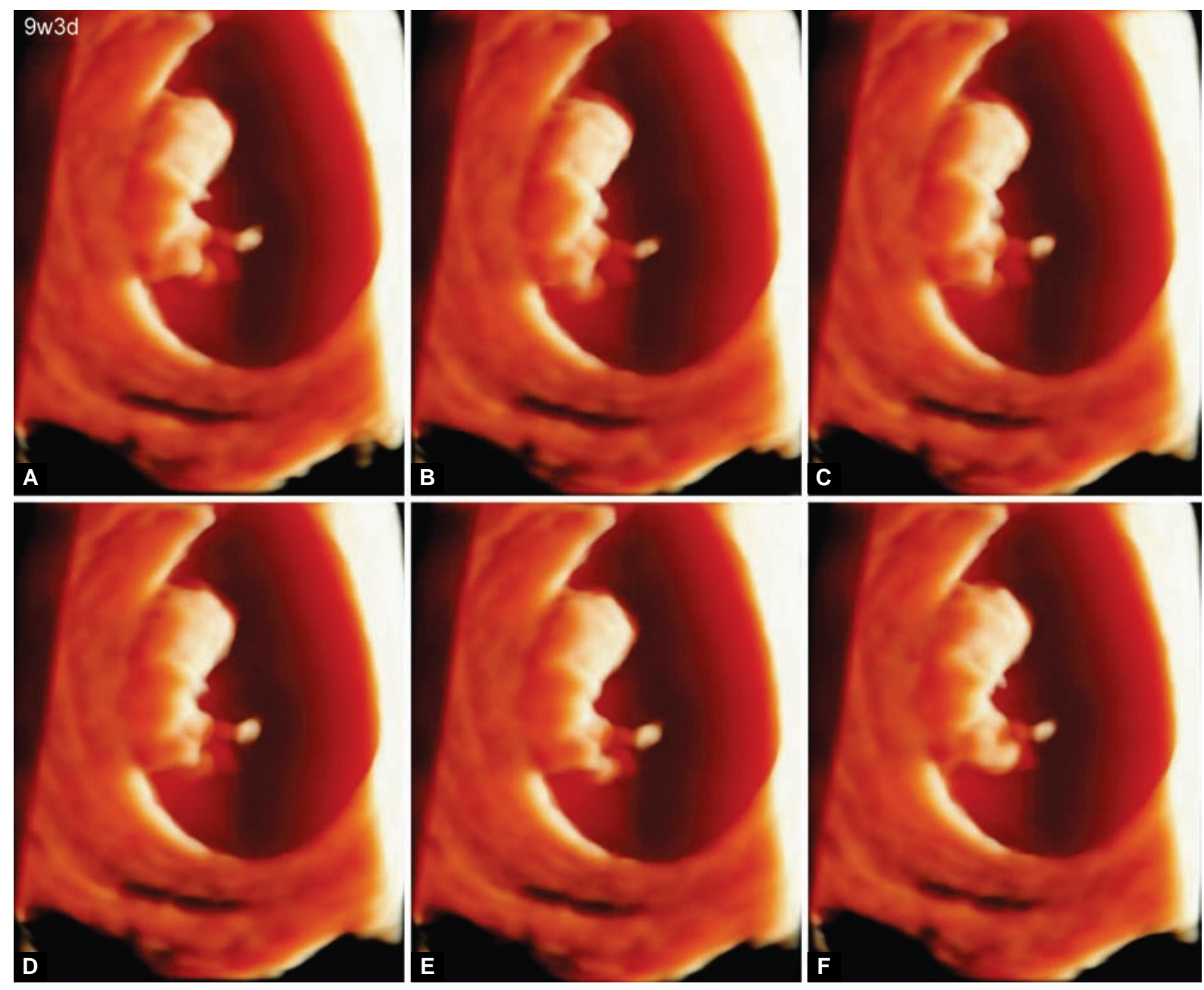

Figs 27A to F: Consecutive HDlive observations of a 9 weeks embryo. Simultaneous occurrence of hand, foot, and trunk movements can be noted at 9 weeks and 3 days
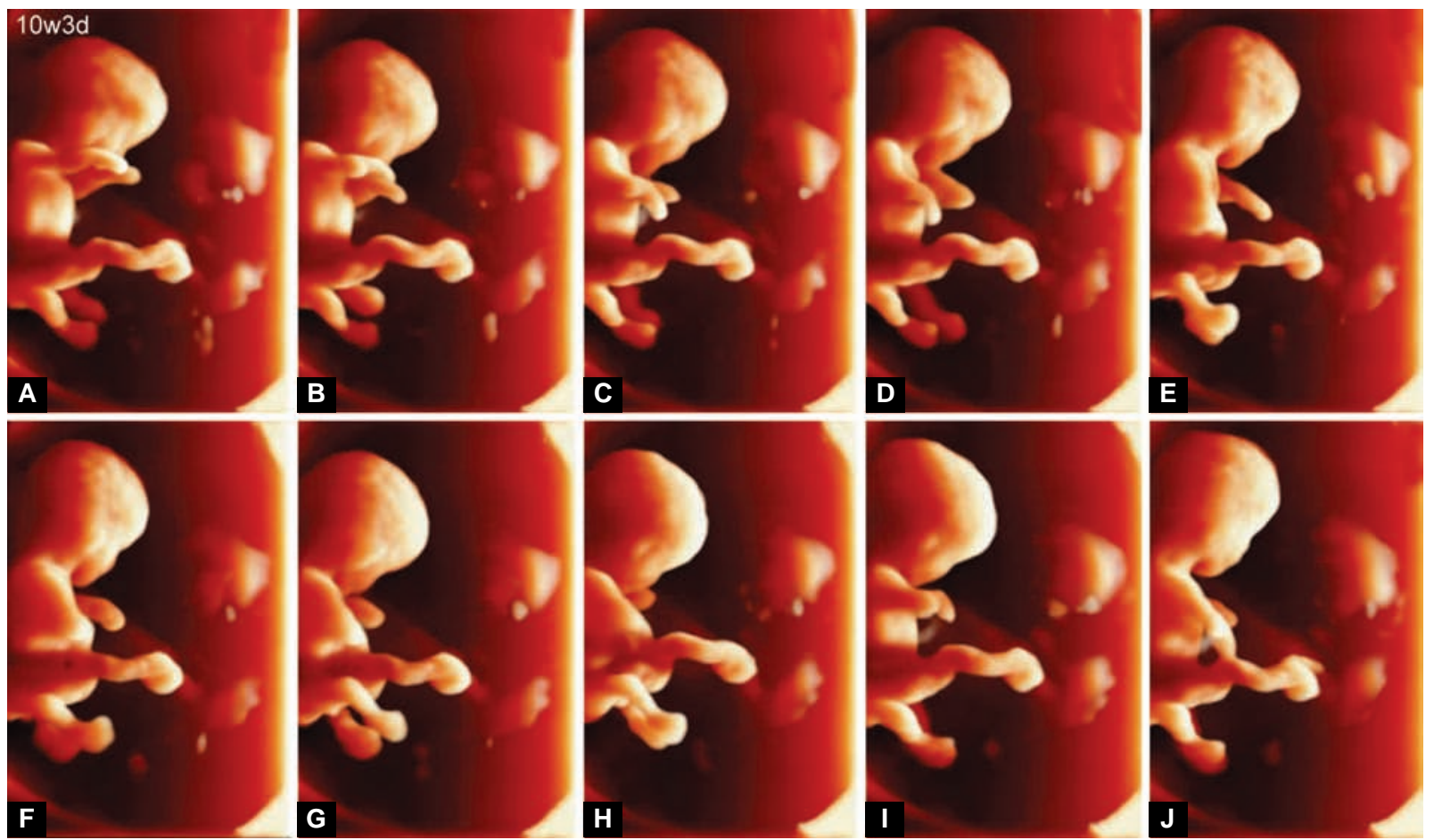

Figs 28A to J: Consecutive HDlive observations of a 10 weeks fetus. Smooth and fluid head and trunk movements involving complicated hand and leg movements can be clearly identified at 10 weeks and 3 days 


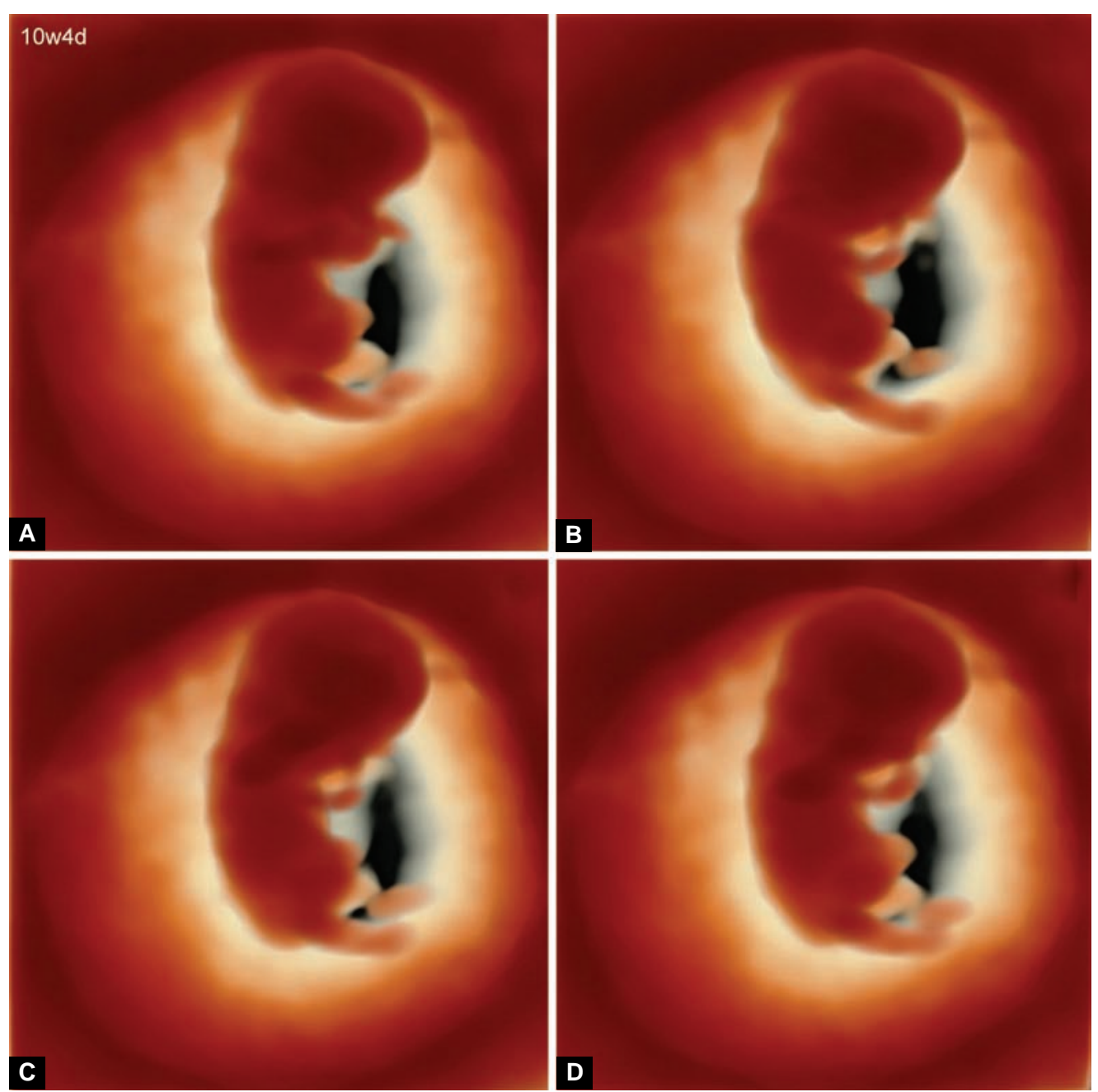

Figs 29A to D: Consecutive HDlive observations of a 10 weeks fetus. Simultaneous occurrence of hand, foot, and trunk movements can be noted at 10 weeks and 4 days

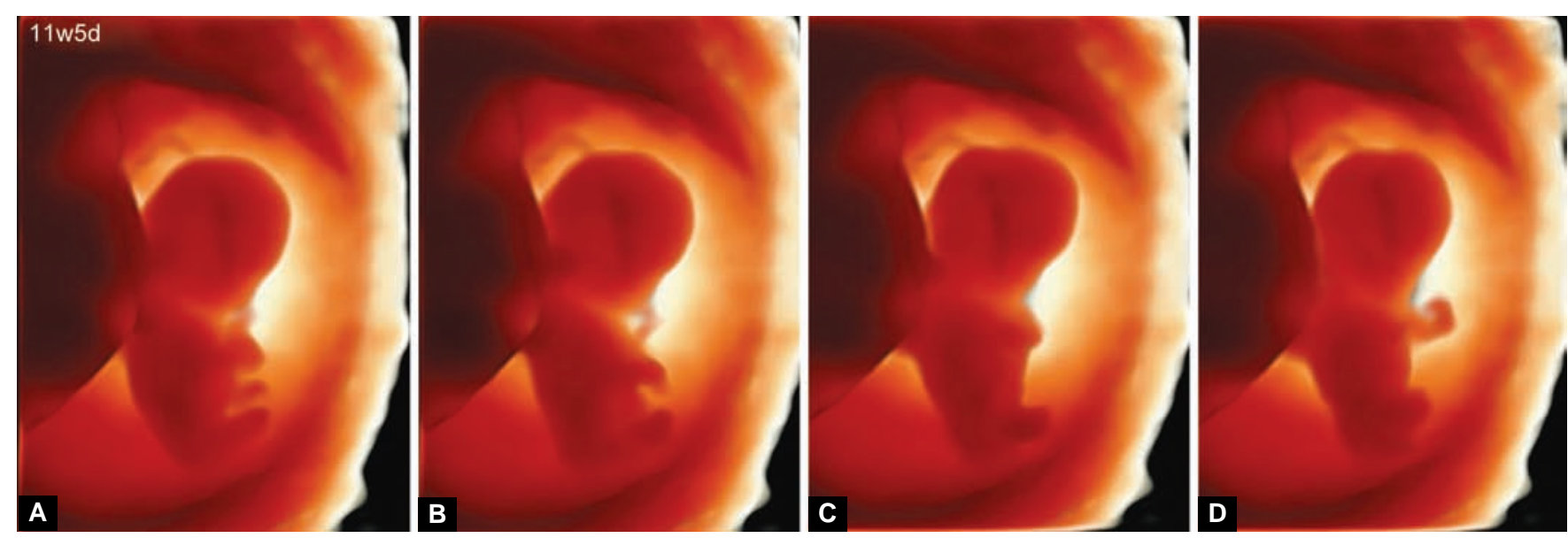

Figs 30A to D: Consecutive HDlive observations of an 11 weeks fetus. Smooth and fluid head and trunk movements involving complicated hand and leg movements can be clearly identified at 11 weeks and 5 days

tongue expulsion (Figs 37 and 38), tongue click (Figs 39A to D), and sucking (Figs 40 and 41) can be clearly observed. In particular, bilateral (see Figs $31 \mathrm{~A}$ and $\mathrm{B}$ ) and unilateral blinking is evident (see Figs 32A and B). Various types of mouth movement, such as yawning (see Figs 35 and 36), swallowing (see Figs 34A to F), chewing, and subtle lip movements (see Figs 33A to F), are recognized. In the course of yawn-like opening of the mouth, tongue movements, such as tongue thrust (see Figs 37 and 38) and tongue click, are noted. In the case of sucking, the fetus sucks his/her fingers (see Fig. 40), and sometimes sucks and/or licks his/her toes (see Figs 41A and B). We can detect new fetal facial 


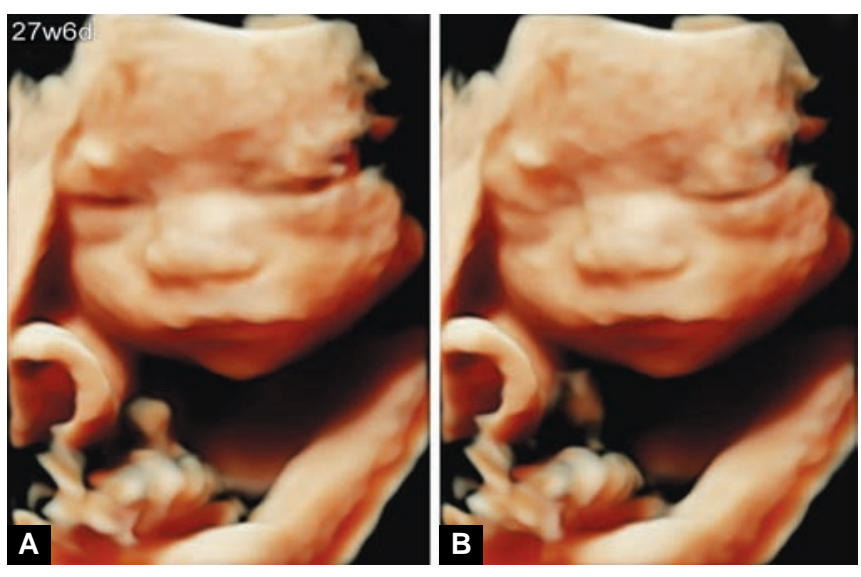

Figs 31A and B: Fetal blinking at 27 weeks and 6 days of gestation: (A) open eyelid; and (B) closed eyelid (Courtesy: Reprinted with permission from Hata $\mathrm{T}$ et al) ${ }^{11}$
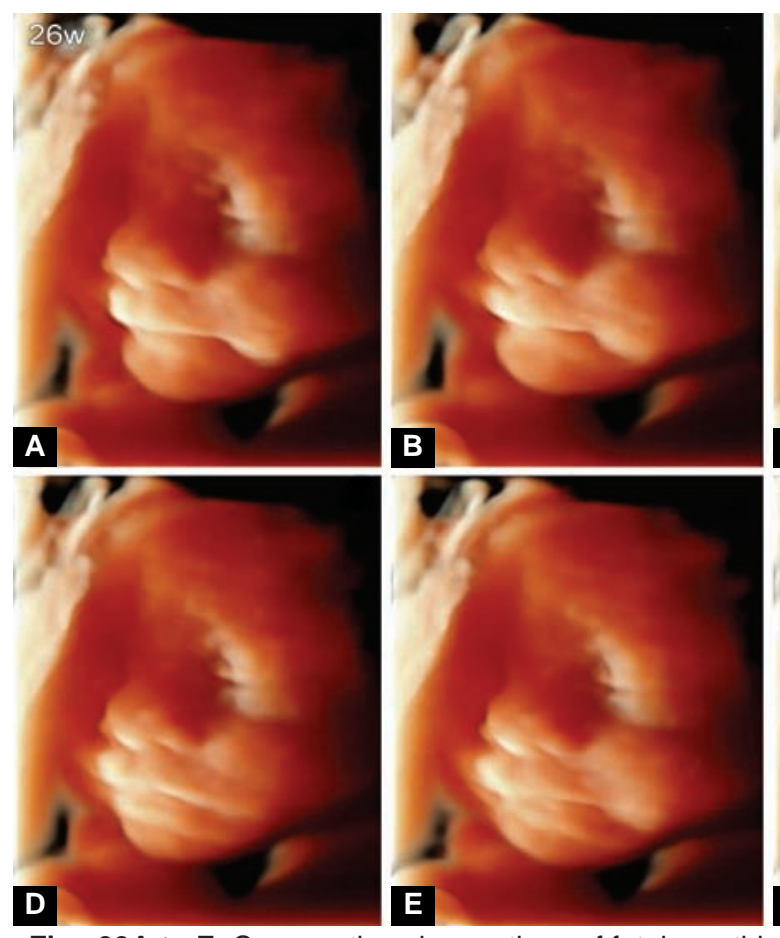

B
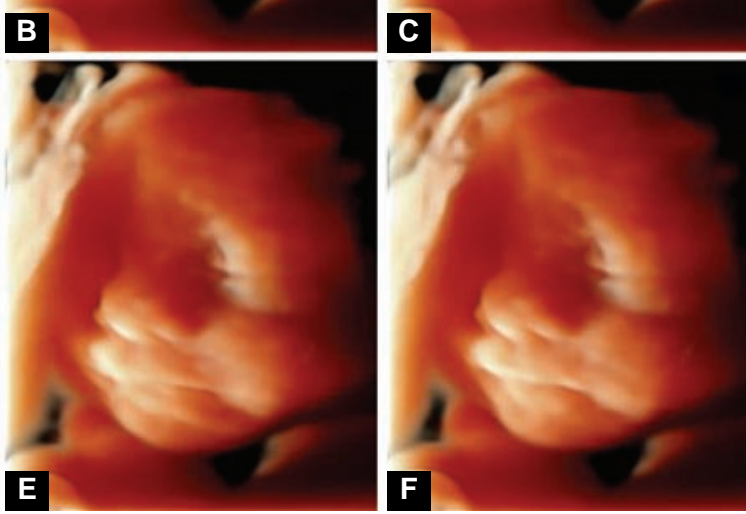

Figs 33A to F: Consecutive observations of fetal mouthing at 26 weeks of gestation

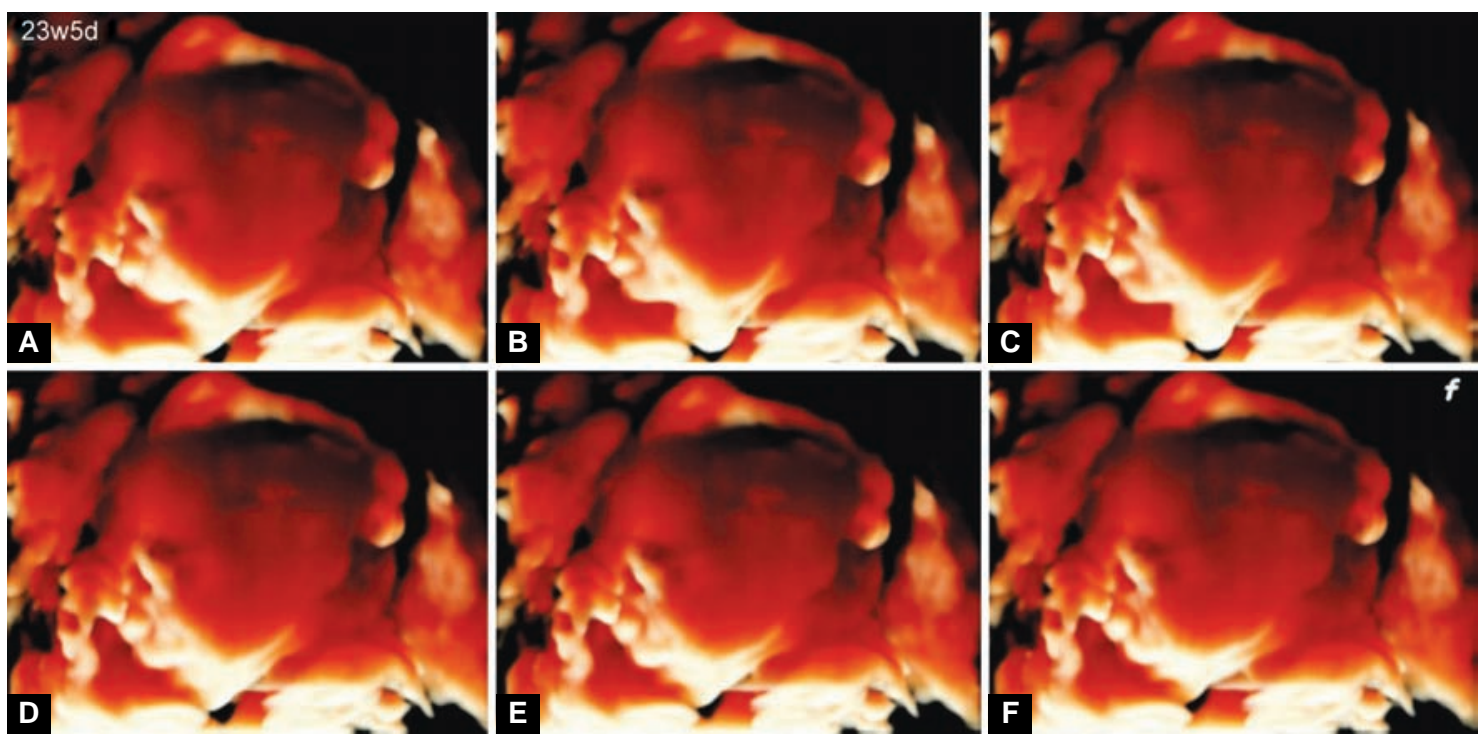

Figs 34A to F: Consecutive observations of fetal swallowing at 23 weeks and 5 days of gestation (Courtesy: Reprinted with permission from Hata T et al) ${ }^{11}$ 

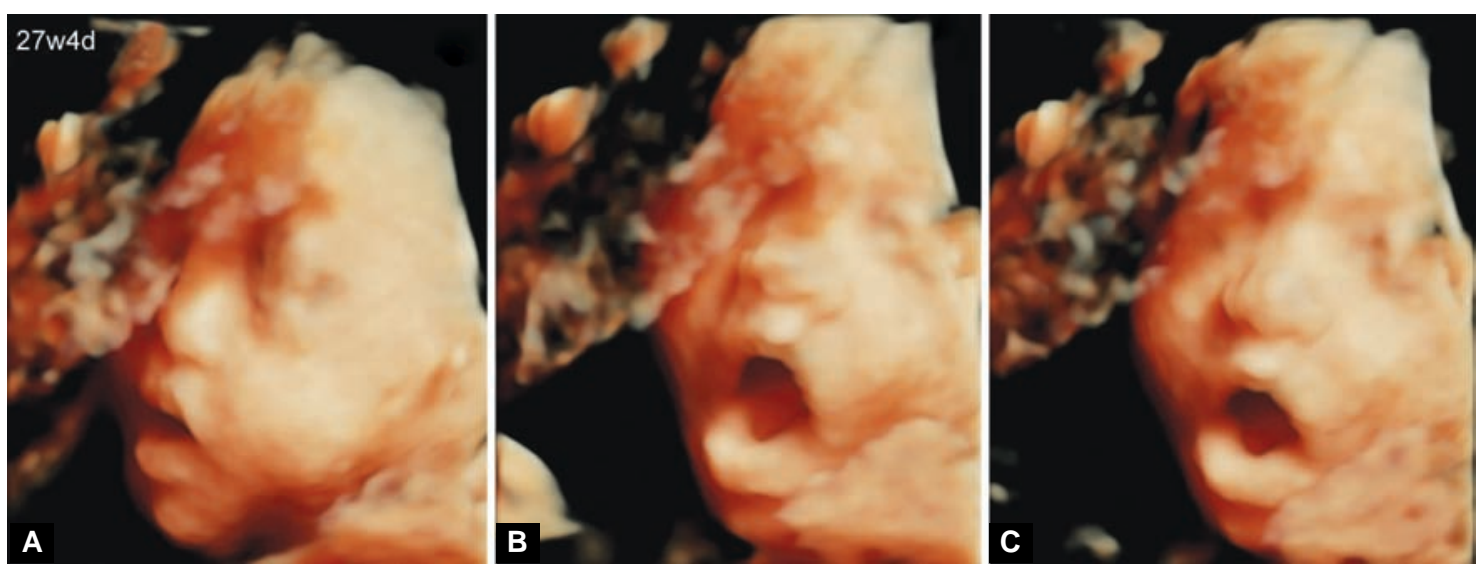

Figs 35A to C: Consecutive observations of fetal yawning at 27 weeks and 4 days of gestation (Courtesy: Reprinted with permission from Hata T et al) ${ }^{11}$
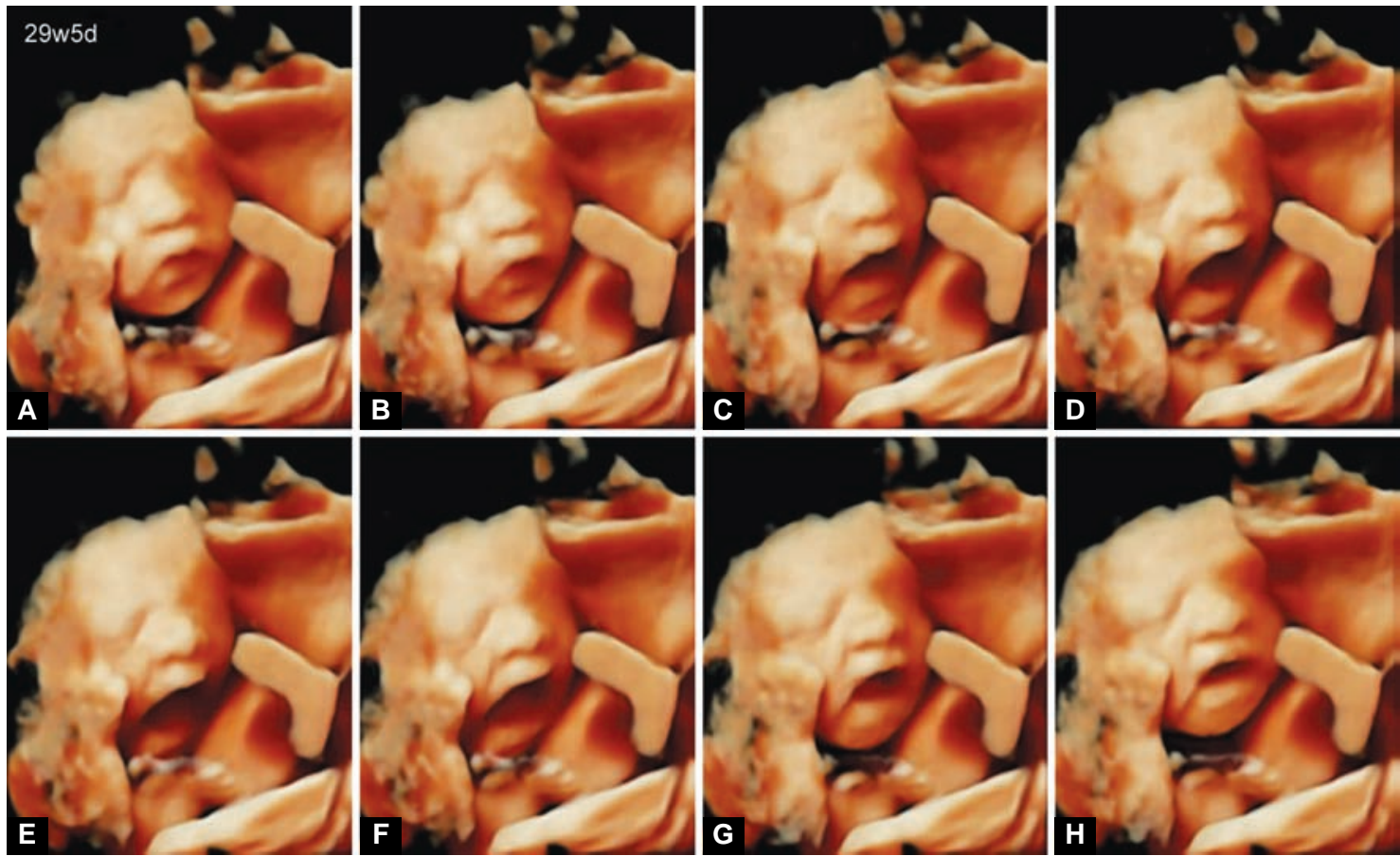

Figs $36 \mathrm{~A}$ to $\mathrm{H}$ : Consecutive observations of fetal yawning at 29 weeks and 5 days of gestation

expressions using HDlive, and have a realistic experience of fetal facial movements.

\section{FETAL EMOTION-LIKE BEHAVIOR}

Realistic fetal emotion-like facial expressions such as smiling-like (Figs 42 and 43) and crying-like (Figs 44 to 46) movements are recognizable. Moreover, fetal emotion-like behaviors using hand-to-face movement, such as the 'joy' pose (Fig. 47), 'self-conscious' pose (Fig. 48), 'thinking' pose like The Thinker by Auguste Rodin (Fig. 49), and 'embarrassed' pose (Figs 50A and B) are evident. 'The question raised here is whether or not facial emotion-like expressions or emotion-like behaviors represent a reliable behavior or emotional state, or simply constitute reflexive behavior on the part of the fetus'. ${ }^{1}$ The answer to this question still remains unresolved. Myowa-Yamakoshi and Takeshita ${ }^{15}$ observed that fetuses opened their mouths before their hands came in contact with their mouths using conventional 4D ultrasound, and suggested the possibility that human fetuses perceive the manner in which they should move their hands to make contact with their mouths. The human fetus is able to feel pain after 24 weeks' gestation, and may feel pain even before that time. ${ }^{16}$ Different fetal facial expressions and movements observed by HDlive might represent some kinds of fetal emotion and awareness. Therefore, we believe that facial emotion-like expressions or emotion-like behaviors represent a reliable behavior or some emotional states of the fetus in utero. Further studies are needed to confirm whether or not the fetus has emotions in utero. 


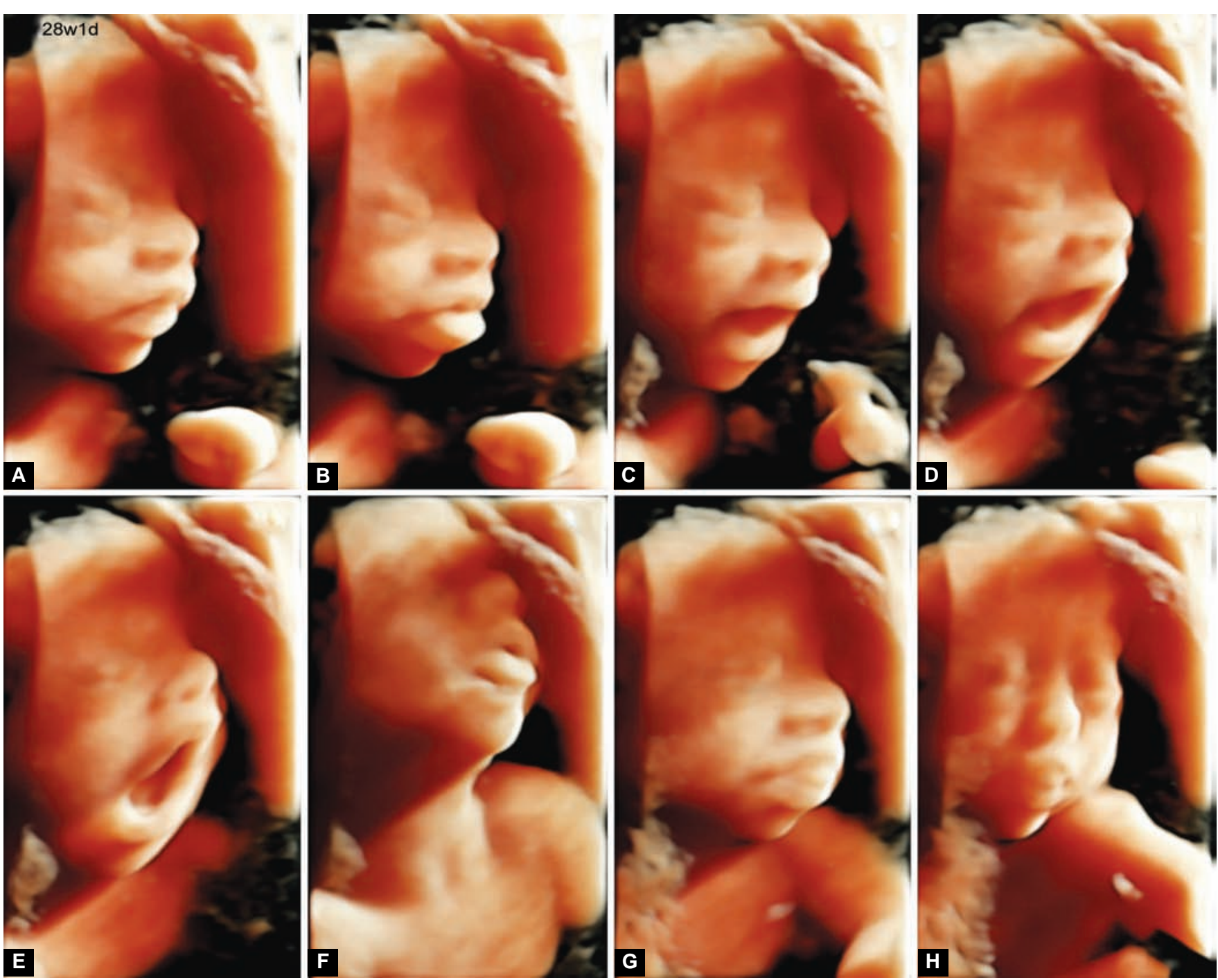

Figs 37A to $\mathrm{H}$ : Consecutive observations of fetal tongue expulsion at 28 weeks and 1 day of gestation. In the course of yawn-like opening of the mouth, tongue expulsion is evident (Courtesy: Reprinted with permission from Hata T et al) ${ }^{11}$
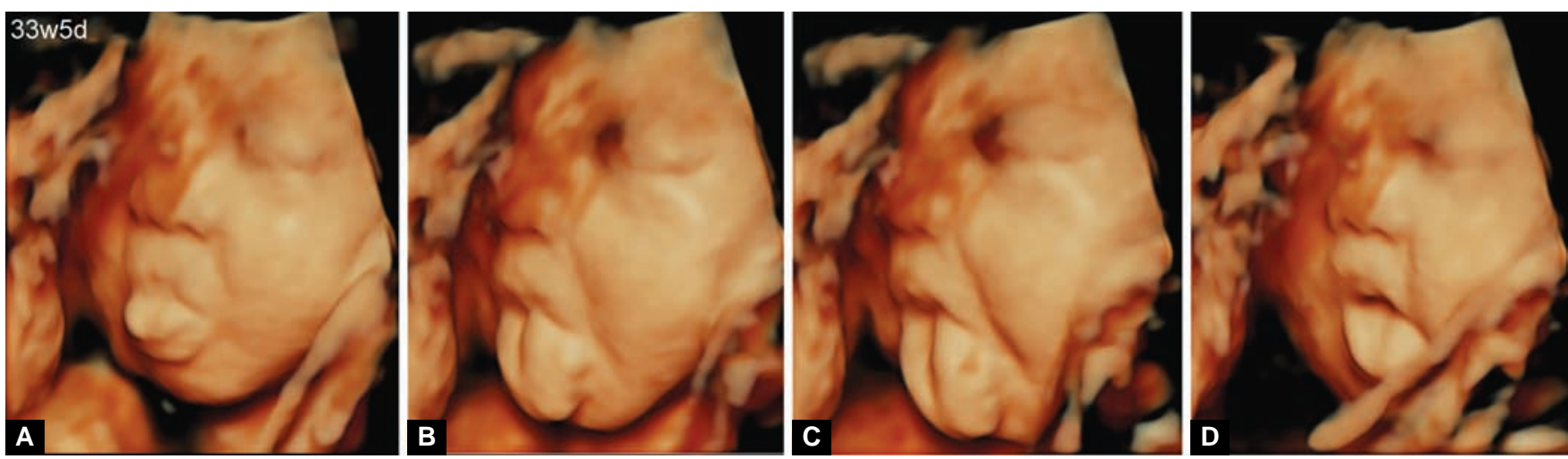

Figs 38A to D: In the course of yawn-like opening of the mouth, tongue thrust can be clearly identified at 33 weeks and 5 days of gestation

\section{CONCLUSION}

HDlive should become an important modality in future fetal behavioral research and in the evaluation of fetal development and well-being. If we become able to observe fetal behavior precisely using this technique, we will be able to obtain new and/or additional information to facilitate improved diagnosis and understanding of the fetal brain function and impairment in utero. Moreover, we may uncover new fetal behavioral functions. Further studies are needed to ascertain the present and future application of this modality to fetal developmental and neurobehavioral assessments. 

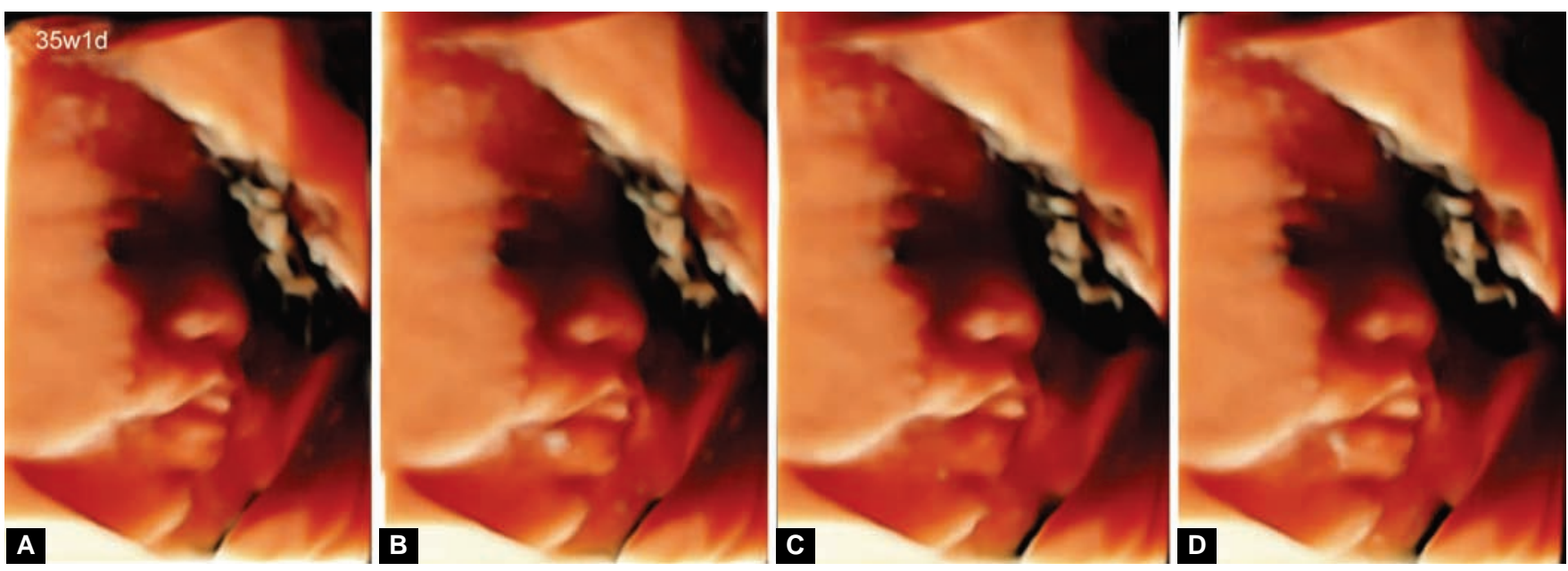

Figs 39A to D: Tongue click at 35 weeks and 1 day of gestation

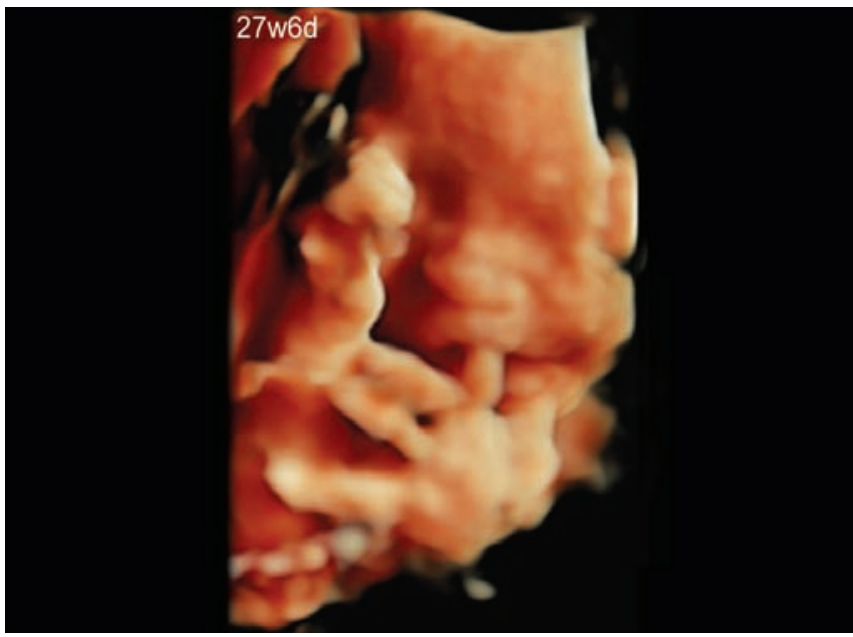

Fig. 40: Fetal sucking at 27 weeks and 6 days of gestation. The fetus sucks his/her fingers
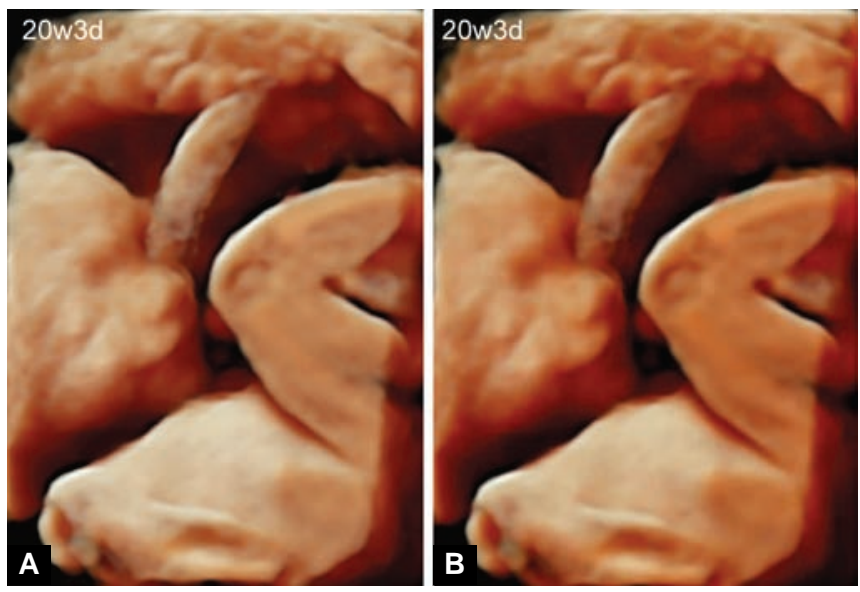

Figs 42A and B: Fetal smiling-like movement at 20 weeks and 3 days of gestation (Courtesy: Reprinted with permission from Hata T et al) ${ }^{11}$

\section{ACKNOWLEDGMENT}

The work reported in this paper was supported by a Grant-inAid for Scientific Research on Innovative Areas 'Constructive
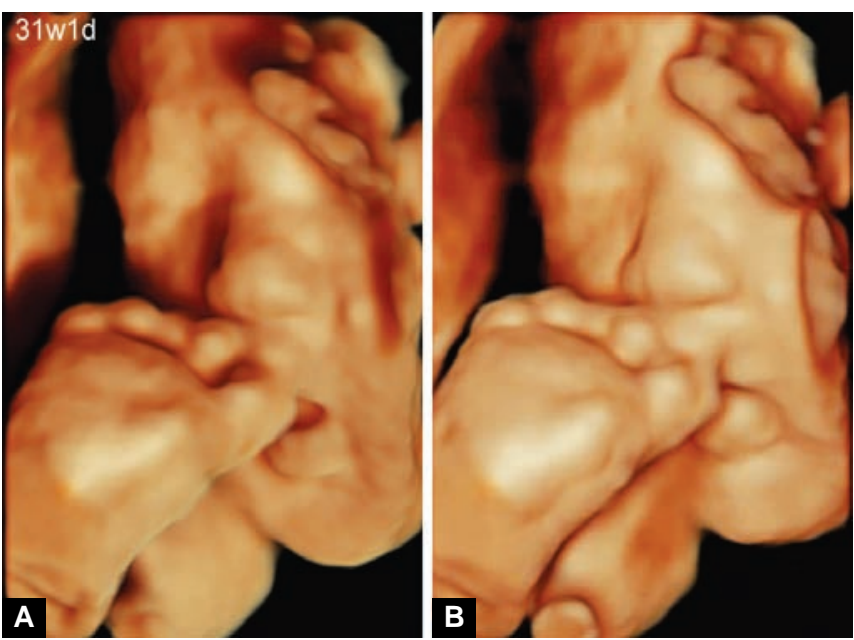

Figs 41A and B: Fetal sucking at 31 weeks and 1 day of gestation. The fetus sometimes sucks $(A)$ and licks his/her toes $(B)$
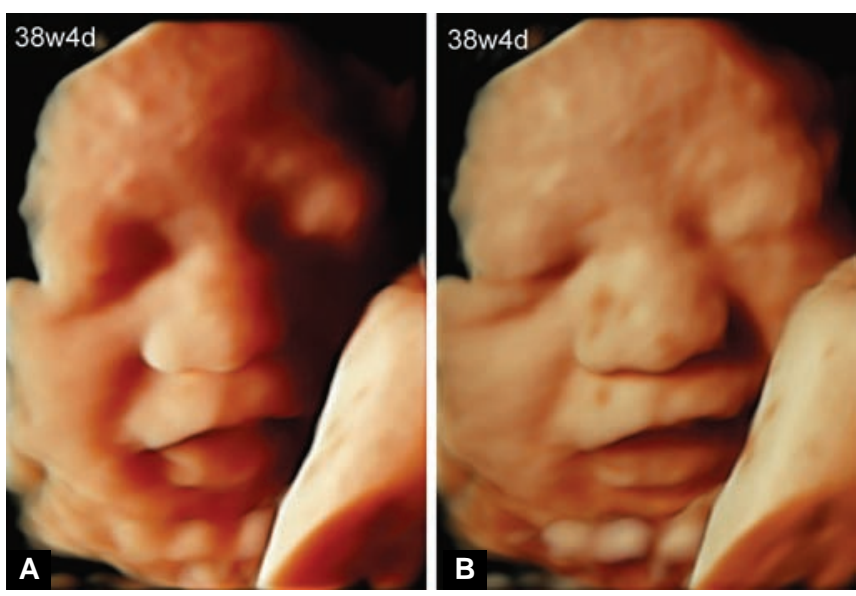

Figs 43A and B: Fetal smiling-like movement at 38 weeks and 4 days of gestation

Developmental Science' (No. 24119004), and a Research Grant (No. 25462561) from The Ministry of Education, Culture, Sports, Science and Technology, Japan. 


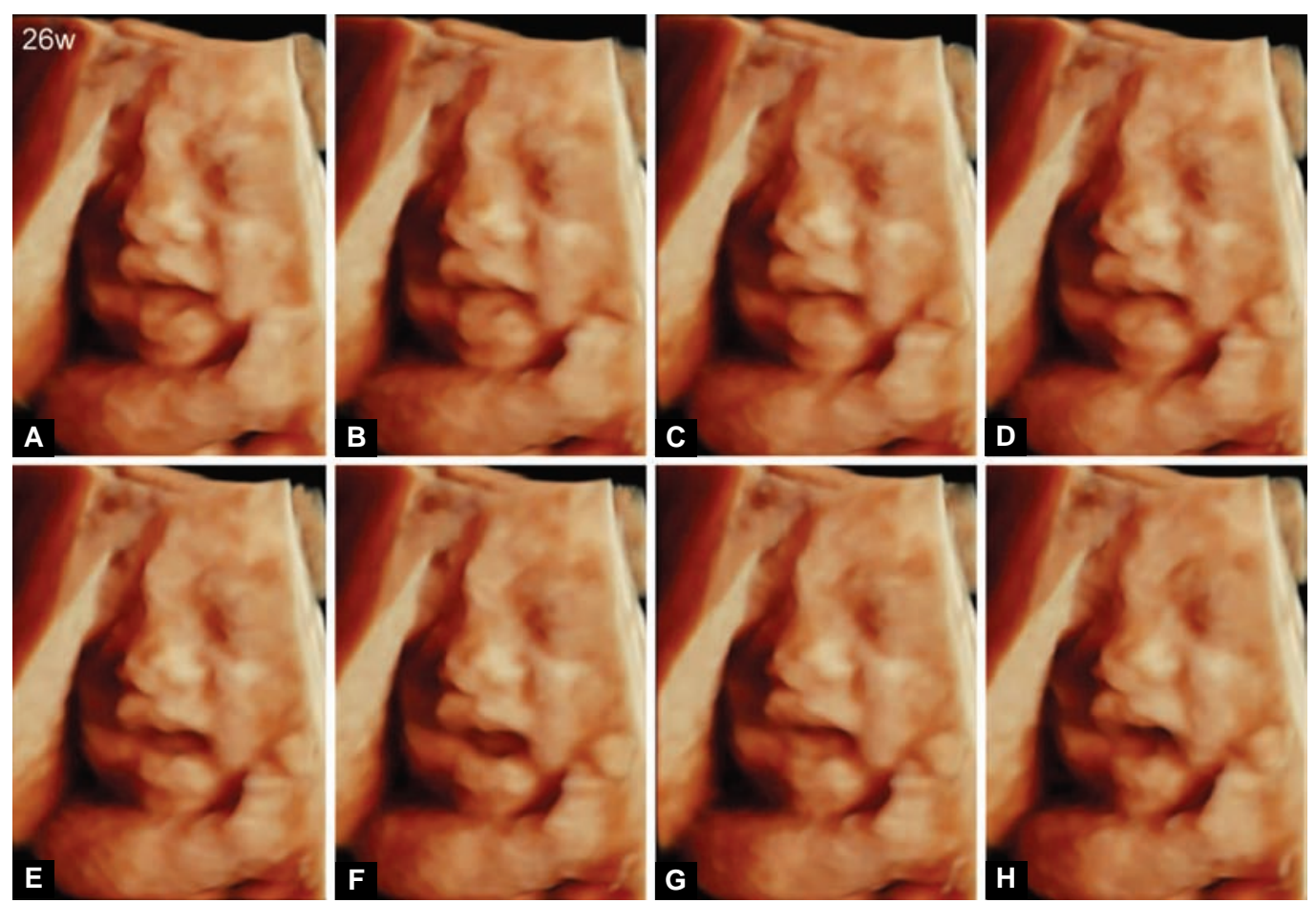

Figs 44A to $\mathrm{H}$ : Consecutive observations of fetal crying-like movement at 26 weeks of gestation
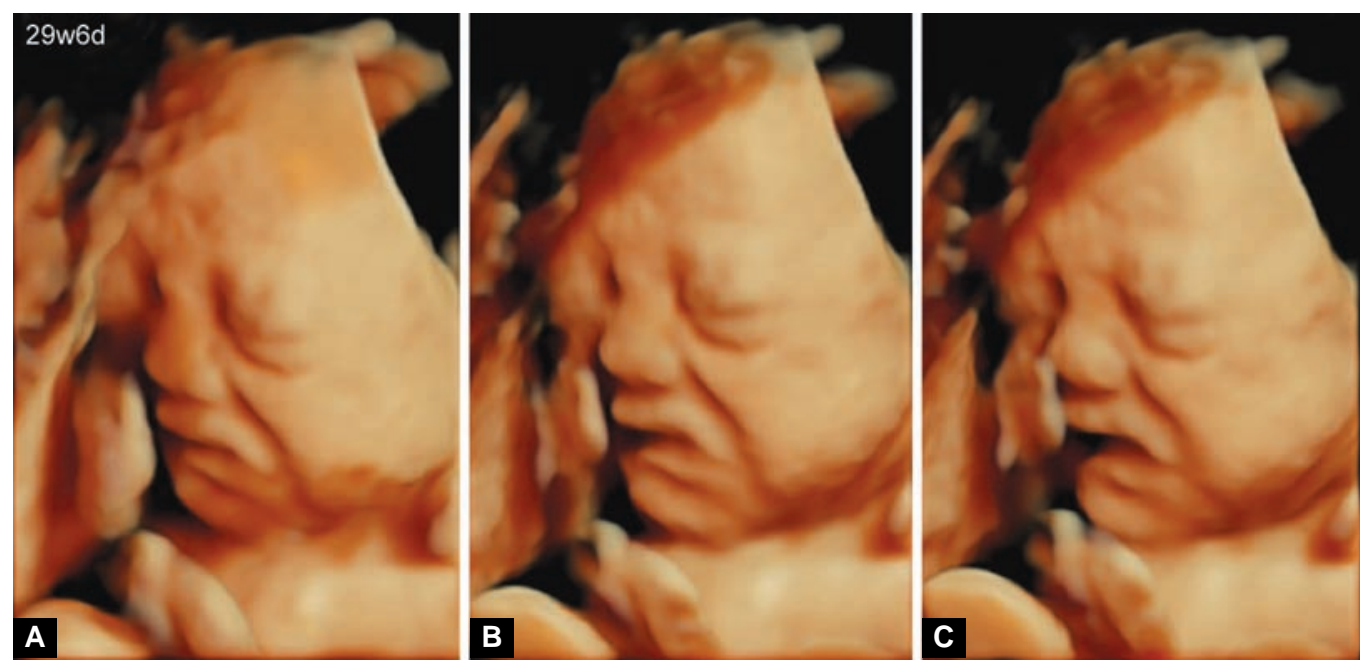

Figs 45A to C: Consecutive observations of fetal crying-like movement at 29 weeks and 6 days of gestation

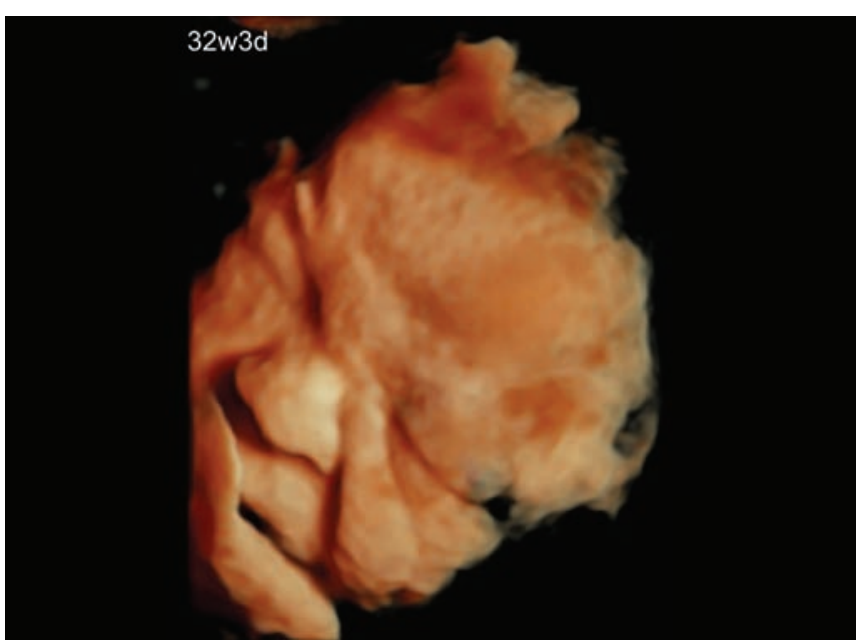

Fig. 46: Fetal crying-like movement at 32 weeks and 3 days of gestation (Courtesy: Reprinted with permission from Hata T et al) ${ }^{11}$

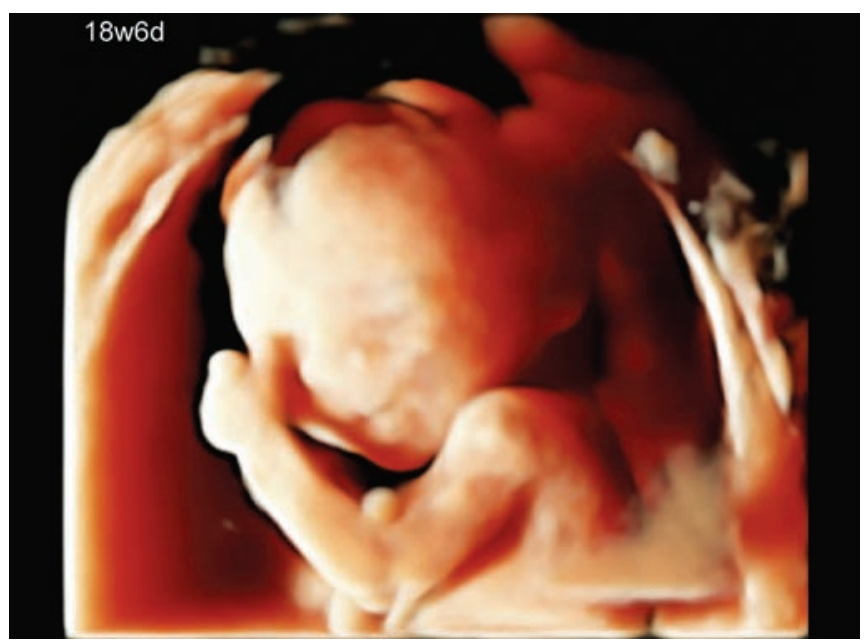

Fig. 47: Fetal emotion-like behavior using hand-to-face movement, such as the 'joy' pose at 18 weeks and 6 days of gestation 


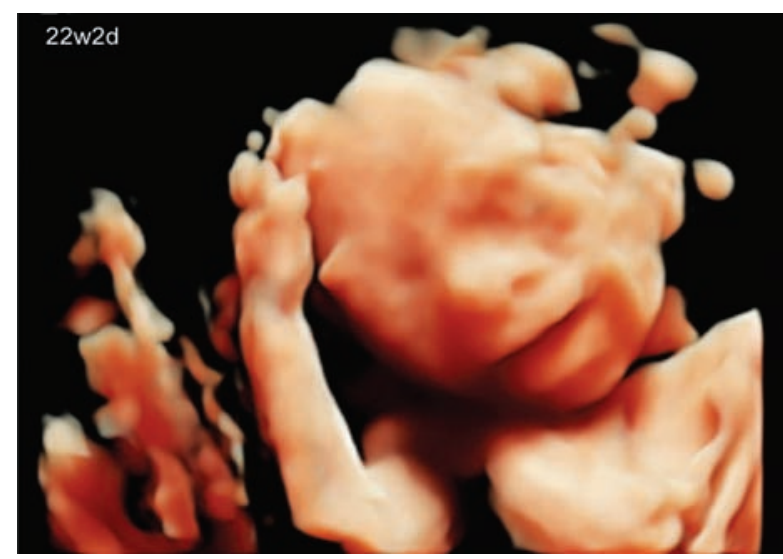

Fig. 48: Fetal emotion-like behavior using hand-to-face movement, such as the 'self-conscious' pose at 22 weeks and 2 days of gestation

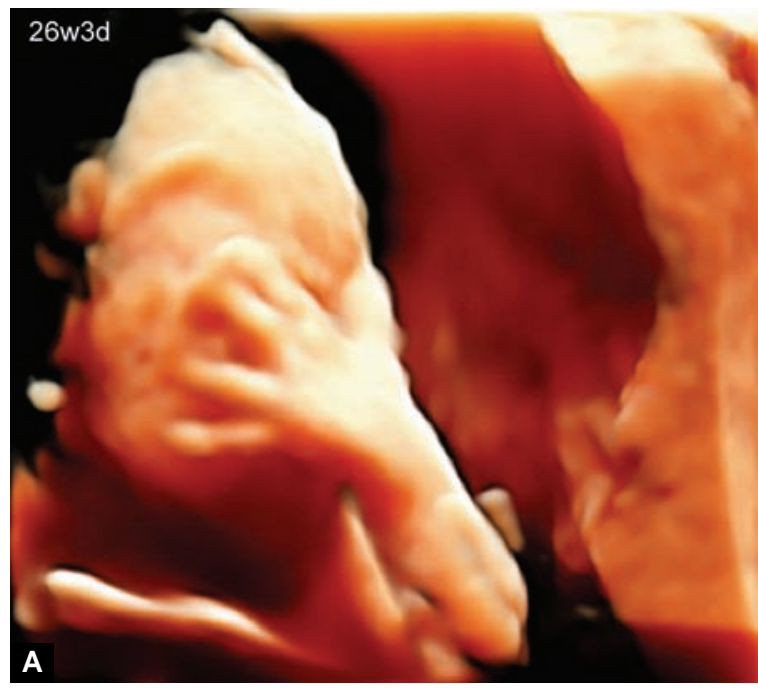

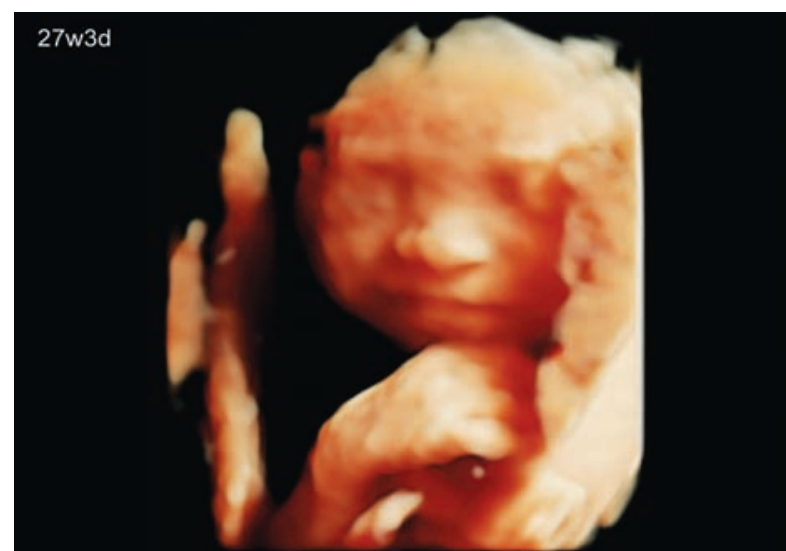

Fig. 49: Fetal emotion-like behavior using hand-to-face movement, such as the 'thinking' pose like 'The Thinker by Auguste Rodin' at 27 weeks and 3 days of gestation

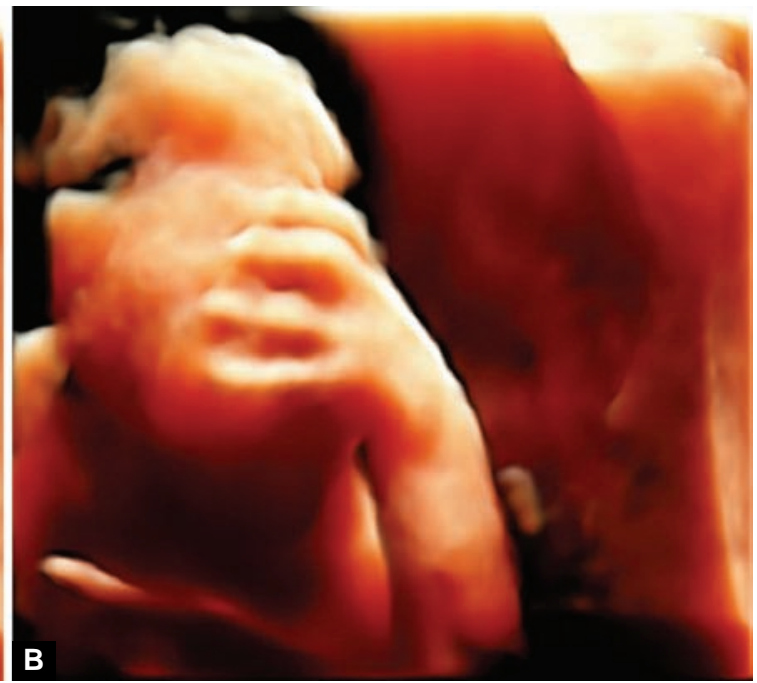

Figs 50A and B: Consecutive HDlive observations of fetal emotion-like behavior using hand-to-face movement, such as the 'embarrassed' pose at 26 weeks and 3 days of gestation

\section{REFERENCES}

1. Hata T, Dai SY, Marumo G. Ultrasound for evaluation of fetal neurobehavioural development: from 2D to 4D ultrasound. Inf Child Dev 2010;19:99-118.

2. Hata T, Kanenishi K, Tanaka H, Marumo G, Sasaki M. Fourdimensional ultrasounds evaluation of fetal neurobehavioral development. Donald School J Ultrasound Obstet Gynecol 2010; 4:233-248.

3. Hata T, Sato M, Kanenishi K, Hanaoka U, Tanaka H. 4D sonography in assessment of fetal neurobehavior. Donald School J Ultrasound Obstet Gynecol 2012;6:121-131.

4. Kagan KO, Pintoffl K, Hoopmann M. First-trimester ultrasound images using HDlive. Ultrasound Obstet Gynecol 2011;38:607.

5. Hata T, Hanaoka U, Tenkumo C, Sato M, Tanaka H, Ishimura M. Three- and four-dimensional HDlive rendering images of normal and abnormal fetuses: pictorial essay. Arch Gynecol Obstet 2012;286:1431-1435.

6. Hata T. HDlive rendering image at 6 weeks of gestation. J Med Ultrasonics 2013;40:495-496.

7. Bonilla-Musoles F, Raga F, Castillo JC, Bonilla FJr, Climent MT, Caballero O. High definition real-time ultrasound (HDlive) of embryonic and fetal malformations before week 16. Donald School J Ultrasound Obstet Gynecol 2013;7:1-8.

8. Bonilla-Musoles F, Raga F, Osborne NG, Bonilla FJr, Caballero O, Climent MT, Wallraf SH, Castillo JC. Multimodality three-dimensional volumetric ultrasound in obstetrics and gynecology with an emphasis in HDlive technique. Ultrasound Q 2013;29:1-13.

9. Grigore M, Mares A. The role of HDlive technology in improving the quality of obstetrical images. Med Ultrason 2013;15:209-214.

10. Merz E. Surface reconstruction of a fetus $(28+2 \mathrm{GW})$ using HDlive technology. Ultraschall Med 2012;33:211-212.

11. Hata T, Hanaoka U, Mashima M, Ishimura M, Marumo G, Kanenishi K. Four-dimensional HDlive rendering image of fetal facial expression: a pictorial essay. J Med Ultrasonics 2013; 40:437-441.

12. Kozuma S. Normal fetal anatomy and development; in Hata T, Kurjak A, Kozuma S (eds): Current Topics on Fetal 3D/4D Ultrasound, Bentham Science Publishers. 2011:1-14. Available at: www.bentham.org/ebooks/9781608050192/index.htm.

13. Hata T, Manabe A, Aoki S, Miyazaki K, Yoshino K, Yamamoto $\mathrm{K}$. Three-dimensional intrauterine sonography in the early firsttrimester of human pregnancy: preliminary study. Hum Reprod 1998; 13:740-743.

14. Reissland N, Francis B, Mason J, Lincoln K. Do facial expressions develop before birth? PLoS ONE 2011;6(8):e24081.

15. Myowa-Yamakoshi M, Takeshita H. Do human fetuses anticipate self-oriented actions? A study by four-dimensional (4D) ultrasonography. Infancy 2006;10:289-301.

16. Katarzyna KK, Miroslaw W. Is fetuses able to feel pain? Ginekol Pol 2011;82:133-136. 